\title{
Comprehensive seismic hazard assessment of Tripura and Mizoram states
}

\author{
T G Sitharam and Arjun SiL* \\ Department of Civil Engineering, Indian Institute of Science, Bangalore 560 012, Karnataka, India. \\ ${ }^{*}$ Corresponding author. e-mail: silarjun@gmail.com
}

Northeast India is one of the most highly seismically active regions in the world with more than seven earthquakes on an average per year of magnitude 5.0 and above. Reliable seismic hazard assessment could provide the necessary design inputs for earthquake resistant design of structures in this region. In this study, deterministic as well as probabilistic methods have been attempted for seismic hazard assessment of Tripura and Mizoram states at bedrock level condition. An updated earthquake catalogue was collected from various national and international seismological agencies for the period from 1731 to 2011. The homogenization, declustering and data completeness analysis of events have been carried out before hazard evaluation. Seismicity parameters have been estimated using G-R relationship for each source zone. Based on the seismicity, tectonic features and fault rupture mechanism, this region was divided into six major subzones. Region specific correlations were used for magnitude conversion for homogenization of earthquake size. Ground motion equations (Atkinson and Boore 2003; Gupta 2010) were validated with the observed PGA (peak ground acceleration) values before use in the hazard evaluation. In this study, the hazard is estimated using linear sources, identified in and around the study area. Results are presented in the form of PGA using both DSHA (deterministic seismic hazard analysis) and PSHA (probabilistic seismic hazard analysis) with 2 and $10 \%$ probability of exceedance in 50 years, and spectral acceleration $(\mathrm{T}=0.2 \mathrm{~s}, 1.0 \mathrm{~s})$ for both the states $(2 \%$ probability of exceedance in 50 years). The results are important to provide inputs for planning risk reduction strategies, for developing risk acceptance criteria and financial analysis for possible damages in the study area with a comprehensive analysis and higher resolution hazard mapping.

\section{Introduction}

India has experienced a number of major earthquakes since ancient times such as great Assam earthquake $\left[\mathrm{M}_{\mathrm{w}} 8.7,1897\right.$, USGS (United State Geological Survey)], Cachar earthquake $\left(\mathrm{M}_{\mathrm{w}} 7.5\right.$, 1869; Oldham 1883), Kangra $\left[\mathrm{M}_{\mathrm{w}}\right.$ 8.6, 1905, IMD (India Meteorological Department)], BiharNepal earthquake $\left(\mathrm{M}_{\mathrm{w}}\right.$ 8.4, 1934, USGS and IMD), Assam-Tibet ( $\mathrm{M}_{\mathrm{w}} 8.7,1950$, USGS), IndoBurma earthquake $\left[\mathrm{M}_{\mathrm{w}} 7.2,1988\right.$, USGS, ISC
(International Seismological Centre)], Latur $\left(\mathrm{M}_{\mathrm{w}}\right.$ 6.4, 1993, NEIC, USGS and ISC), Bhuj earthquake $\left(\mathrm{M}_{\mathrm{w}}\right.$ 7.6, 2001, IMD), Kashmir earthquake $\left(\mathrm{M}_{\mathrm{w}}\right.$ 7.4, 2005, IMD), and Sikkim earthquake $\left(\mathrm{M}_{\mathrm{w}} 6.9\right.$, 2011, IMD and USGS). Moreover, the earthquakes that are triggered in neighbouring countries are also influencing Indian soil. For example, SumatraAndaman earthquake $\left(\mathrm{M}_{\mathrm{w}}\right.$ 9.1) that occurred on 26 December 2004, hit the coastal region of south India around the Indian Ocean, and killed approximately 0.283 million people (source: USGS

Keywords. Catalogue; completeness analysis; attenuation equation; seismic source; DSHA and PSHA; PGA; spectral acceleration. 
2005). However, this destructive earthquake caused severe ground shaking in all neighbouring countries (India, Malaysia, Thailand, Burma, Indonesia, and Bangladesh). Moreover, in the 2011 earthquake in Sendai, Japan, more than 16,000 were reported dead with an insured loss of over 34 billion (RMS 2011). The impacts of these earthquakes have attracted the attention of many researchers and engineers towards the seismic safety evaluation of the region. After the Bhuj earthquake, the Bureau of Indian Standards (BIS) has revised the Indian seismic code (IS: 1893-2002). The newly revised code divides the whole country (India) into four seismic zones (Zone II-0.1 g, III-0.16 g, IV$0.24 \mathrm{~g}$, and $\mathrm{V}-0.36 \mathrm{~g}$ ) assigning different levels of seismicity in terms of zone factor, which is twice the zero period acceleration (ZPA) of the design spectrum.

An earthquake is a major natural threat to mankind killing thousands of people every year with the destruction and collapse of buildings causing economic losses in different parts of the globe. The seismic safety of the infrastructure such as hospitals, bridges, dams, nuclear power plants, schools, transportation facilities, and other lifeline structures is of prime importance in terms of life and property. These structures should be designed and constructed carefully to withstand earthquake loads with minimum or no damages. Site-specific seismic hazard analysis could offer realistic design inputs for larger expected events in the future to mitigate the hazard in a better way. The knowledge of geological and seismological aspects and reliable methods is required for hazard evaluation of a region. There are two well-known methods that are widely used for seismic hazard assessment, i.e., DSHA and PSHA (Cornell 1968). In DSHA, hazard is evaluated considering the close distance between the source and site of interest and maximum magnitude occurred within the fault. The use of observed maximum magnitude with an increment of 0.5 units is recommended by Gupta (2002) for evaluation of seismic hazard and this approach has been implemented/adopted by Iyengar and Ghosh (2004), Raghu Kanth and Iyengar (2006, 2007), and Kolathayar et al. (2012) for seismic hazard evaluation of Delhi, Mumbai and the entire Indian region. Sitharam and Anbazhagan (2009) produced the seismic hazard map for Bangalore considering both DSHA and PSHA. Suganthi and Boominathan (2006) developed the seismic hazard map for Chennai city. However, in the present work, maximum magnitude has been estimated considering several appropriate techniques.

On the other hand, for all important and critical infrastructure projects, DSHA is known as the simplest method for seismic hazard evaluation (Maulchin 2005). The major drawback of this method is that, it does not talk about the variability/uncertainty with space and time (i.e., where, when, and what would be the size of the event). In probabilistic hazard analysis (PSHA), epistemic and aleatory uncertainties can be accounted for within a probabilistic framework. The PSHA procedure assumes that the distance and magnitude probabilities are distributed uniformly throughout the fault rupture.

However, in the present analysis, both DSHA and PSHA have been adopted to have a clear picture about the degree of variability of the hazard in the same location of the study area. This will help the structural engineers in safe earthquake resistant structural design; planners to decide the location of important structures, and the government to take appropriate decisions regarding disaster mitigation planning. Therefore, the final results are presented together with higher resolution at the micro level (a finer size of grid $0.05^{\circ} \times 0.05^{\circ}$ was used to estimate the seismic hazard, instead of using an interpolation technique. The hazard is estimated at the centre of each grid which gives an absolute hazard value) in the states (Tripura and Mizoram) using both the techniques.

\section{Status of the study area and seismotectonic setup}

Our present study focuses on the hazard analysis of Tripura and Mizoram states; which are two among eight northeastern states in India. We have considered the study area extending $500 \mathrm{~km}$ radius from the political boundaries of the mentioned states (latitude $18.40^{\circ}-29^{\circ} \mathrm{N}$ and longitude $86.20^{\circ}-$ $97.30^{\circ} \mathrm{E}$ ) shown in figure 1 . The hazard studies of northeastern states like, Sikkim, Assam and Manipur have been carried out by various researchers in the past (Nath 2006, 2007; Raghu Kanth et al. 2008; Nath et al. 2009; Pallav 2010). Seismically, northeast India is one of the six most active tectonic plates in the world (Kayal 1998; Tiwari 2000). It is well established that the Indian plate is continuously dipping down under the Eurasian plate, which is caused by the formation of the Himalayas (Tandon and Srivastava 1975; Oldham 1882, 1899; Kayal 1987; Mukhopadhyay and Dasgupta 1988; Mukhopadhyay 1992; Nandy 2001; Kumar et al. 2005; Mitra et al. 2005). The rate of movement between the Indian and the Eurasian plates converge to about $45-50 \mathrm{~mm} /$ year (Kumar et al. 2007). The latest version of the seismic zoning map of India given in the earthquake resistant design code of India [BIS 1893 (Part 1)] assigns four levels of shaking intensity for the entire India in terms of different zone factors. The study 


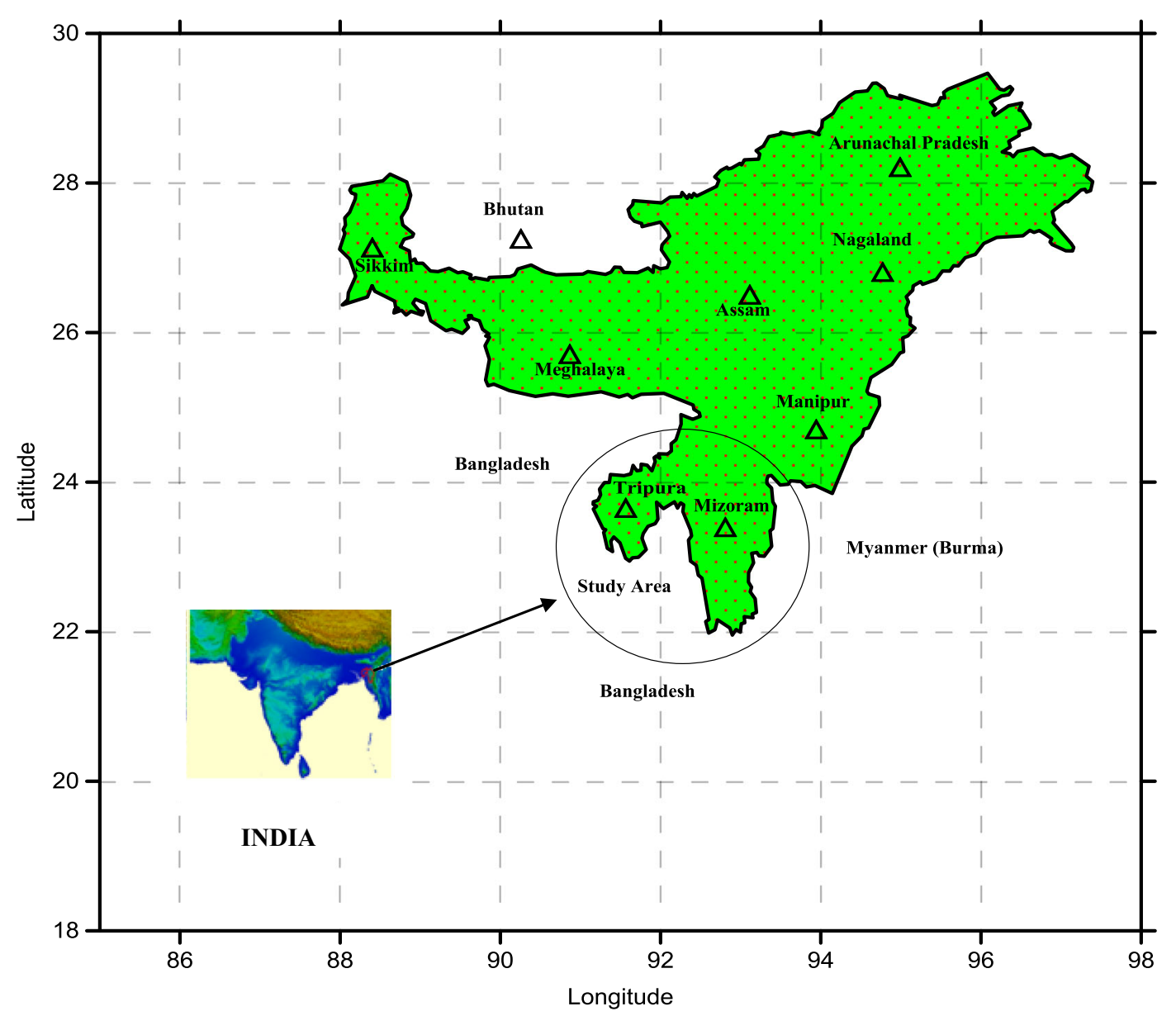

Figure 1. Location map of the study area (1:1M scale). (Geographical boundaries shown in the figure are approximate.)

region has been placed in a seismic zone $\mathrm{V}$ as per BIS: 1893-2002, which has the highest zone factor in the country. The main drawback of the seismic zonation code of India (BIS: 1893, 2002) is that, it is based on the past seismic activity and not based on a comprehensive seismic hazard analysis. In the study area, five historical earthquakes of $\mathrm{M}_{\mathrm{w}}>8$ and 15 events of magnitude $\mathrm{M}_{\mathrm{w}}>7$ have occurred since 1731 to 2011, which are listed in table 1.

However, a diverse tectonic environment is observed in northeast India where spontaneous seismic activities are going on in different junctions of plates or plate boundaries from the Himalayan belt to Andaman range. The Himalayan belt is under a continental collision between the Indian and the Eurasian plates that stands on the north side of the study area, which extends towards the east to west direction. Intraplate activities are also observed within this region (Shillong Plateau region). Most frequent activities are reported from Indo-Burma Range which is seismically more active. Subduction activities are continuing in this belt which extends up to $1100 \mathrm{~km}$ in length towards north to south direction from Burma to Andaman and finally meets the Australian plate. Therefore, the tectonic framework of this region is more complex because of the diverse tectonic characteristics. The differential movements of the plates are capable of producing future ground motion that could severely damage the area. However, in the recent past, researchers have found a seismic gap known as Assam gap (Khattri and Weiss 1978; Khattri and Tyagi 1993). Since 1950, no major event has been recorded in between the Eastern Himalaya (EH), Shillong Plateau (SP) and in the Indo-Burmese Range (IBR). Khattri and Weiss (1978) have suggested and are expecting a similar or higher magnitude earthquake in this region at any time in the future. In 2011, both the states have experienced 37 earthquakes of which, there were five big earthquakes of magnitudes M 6.4 (4 February 2011), M 6.7 (24 March 2011), M 6.9 (18 September 2011), M 6.4 (30 October 2011), and M 6.9 (13 December 2011) (source: IMD). The earthquake (M 6.9) that has occurred on 18 September 2011 known as Sikkim earthquake has caused huge destructions (building collapse, landslides, causalities, disruption of connectivity by road, and other infrastructural damages) in the Sikkim state. 
Table 1. Number of earthquakes (main shocks) reported of the study area until 2011.

\begin{tabular}{|c|c|c|c|c|c|c|c|c|}
\hline From & To & $\mathrm{M}_{\mathrm{w}}<4$ & $4<\mathrm{M}_{\mathrm{w}}<5$ & $5<\mathrm{M}_{\mathrm{w}}<6$ & $6<\mathrm{M}_{\mathrm{w}}<7$ & $7<\mathrm{M}_{\mathrm{w}}<8$ & $\mathrm{M}_{\mathrm{w}}>8$ & Total \\
\hline 1731 & 1740 & - & - & - & - & 1 & - & 1 \\
\hline 1741 & 1750 & - & - & - & - & - & - & 0 \\
\hline 1751 & 1760 & - & - & - & - & - & - & 0 \\
\hline 1761 & 1770 & - & 1 & - & 2 & - & - & 3 \\
\hline 1771 & 1780 & - & - & - & - & - & - & 0 \\
\hline 1781 & 1790 & - & - & - & - & - & - & 0 \\
\hline 1791 & 1800 & - & - & - & - & - & - & 0 \\
\hline 1801 & 1810 & 1 & 2 & - & - & - & - & 3 \\
\hline 1811 & 1820 & - & - & 2 & - & - & - & 2 \\
\hline 1821 & 1830 & - & 6 & 4 & 1 & - & - & 11 \\
\hline 1831 & 1840 & - & - & 1 & 1 & 1 & 1 & 4 \\
\hline 1841 & 1850 & 2 & 3 & 8 & 1 & 1 & - & 15 \\
\hline 1851 & 1860 & 1 & 1 & 2 & 2 & - & - & 6 \\
\hline 1861 & 1870 & - & 2 & 5 & 2 & 1 & - & 10 \\
\hline 1871 & 1880 & - & - & 1 & - & - & - & 1 \\
\hline 1881 & 1890 & - & 1 & 1 & 1 & - & - & 3 \\
\hline 1891 & 1900 & - & 1 & - & - & - & 1 & 2 \\
\hline 1901 & 1910 & - & - & 2 & - & 1 & 1 & 4 \\
\hline 1911 & 1920 & - & - & 1 & 1 & 1 & - & 3 \\
\hline 1921 & 1930 & - & - & 9 & 14 & 2 & - & 25 \\
\hline 1931 & 1940 & - & - & 7 & 17 & 2 & 1 & 27 \\
\hline 1941 & 1950 & - & - & 12 & 7 & 1 & 1 & 21 \\
\hline 1951 & 1960 & - & - & 17 & 8 & 1 & - & 26 \\
\hline 1961 & 1970 & - & 23 & 93 & 20 & - & - & 136 \\
\hline 1971 & 1980 & 7 & 129 & 146 & 8 & - & - & 290 \\
\hline 1981 & 1990 & 40 & 268 & 293 & 16 & 2 & - & 619 \\
\hline 1991 & 2000 & 321 & 581 & 287 & 22 & 1 & - & 1212 \\
\hline 2001 & 2010 & 453 & 260 & 104 & 5 & - & - & 822 \\
\hline \multirow[t]{2}{*}{2011} & & & 1 & 1 & 3 & & & 5 \\
\hline & Total & 825 & 1279 & 996 & 131 & 15 & 5 & 3251 \\
\hline
\end{tabular}

Although many researchers have reported the status of seismicity in the northeastern region of India, only a very few studies have been carried out for Tripura and Mizoram region. Earlier works have been reported in the city of Guwahati by Nath et al. (2009, 2011) and Raghu Kanth and Dash (2010) for Sikkim, and for Manipur, Pallav (2010). Further, Nath and Thingbaijam (2011) produced peak ground motion predictions in India. PCRSMJUA (2005) presented the DSHA-based seismic hazard map for Jabalpur city.

From a review of available literature, no specific study exists for Tripura and Mizoram till date, whereas almost the whole of the study area is highly vulnerable to severe shaking and amplification due to earthquakes. Because of the increasing population and rapid mushrooming of unplanned urban infrastructure that inhabits this region, it becomes prudent to carry out the seismic hazard analysis of Tripura and Mizoram states, which will assist the designers/planners and the government to mitigate the hazard.

\section{Inputs for seismic hazard assessment}

\subsection{Earthquake catalogue}

The earthquake catalogue includes the details of each event, like location of occurrences in terms of coordinates; depth, magnitude in terms of the $\mathrm{M}_{\mathrm{L}}, \mathrm{M}_{\mathrm{b}}, \mathrm{M}_{\mathrm{s}}$ and time of occurrences. In northeast India, Department of Science and Technology (DST) has set up a seismic network or seismic array known as Shillong array since 1985 which is maintained by IIT, Roorkee. The Shillong array is involved in detecting only strong motion events (for high frequency motion) of this region (northeast India). For evaluating reliable values of region specific seismicity parameters and other important seismological parameters such as stress drop, quality factor, and frequency range, a good quantity of ground motion database/events (consisting of all types of frequency ranges of motion) is essential. There are two types of events/databases available: pre-instrumental (historic) and instrumental 
catalogue. Pre-instrumental data are available for damaging events and are collected from literature (Basu 1964; Rastogi 1974; Chandra 1977; Oldham 1883; Dunbar et al. 1992; Bilham 2004). The instrumental catalogue was collected from various national and international seismological agencies. The national agencies are the IMD, Bhabha Atomic Research Centre (BARC), National Geophysical Research Institute (NGRI). International seismological agencies are the ISC, USGS and Cosmos Virtual Data Center. The catalogue used in the study area ranges from latitude $18.40^{\circ}-$ $29.0^{\circ} \mathrm{N}$ and longitude $86.20^{\circ}-97.30^{\circ} \mathrm{N}$. A total of 27,921 earthquake events were collected from those seismological agencies having different magnitude scales. In our clustered catalogue processing, many events were repeated several times and these were removed from the database. The remaining amounts of data need declustering for identification of main shocks, homogenization of catalogue, evaluation of seismicity status, and hazard evaluation. The earthquake catalogue was declustered using the methodology proposed by Gardner and Knopoff (1974) modified by Uhrhammer (1986). Gardner and Knopoff (1974) describe the method as follows: For declustering the catalogue with Gardner and Knopoff method, the catalogue has to be divided into clusters. Considering all the events in a chronological order, if the $i$ th event is in the window of a preceding larger shock that has not been removed, that has to be removed. If a larger shock is in the window of the $i$ th event, all the events ( $i$ th event) except the largest shall be removed, else the $i$ th event will be retained. The space and time window used to remove foreshocks and aftershocks are: distance $=\mathrm{e}_{\mathrm{w}}^{-1.024+0.804^{*} \mathrm{M}}$ and time $=\mathrm{e}_{\mathrm{w}}^{-2.87+1.235^{*} \mathrm{M}}$. This algorithm assumes that the time and spatial distribution of foreshocks and aftershocks are dependent on the magnitude of the main event. However, in our compiled database, some of the catalogues were reported in $\mathrm{M}_{\mathrm{w}}$ as well as other magnitude scales from various agencies. These catalogues were used to develop new region-specific correlations (northeast India) for the homogenization of the catalogue. Homogenization is the process of converting different types of magnitude scales into a single common magnitude known as moment magnitude $\left(\mathrm{M}_{\mathrm{w}}\right)$. Using the available database, an attempt has been made to fit the data in a simple linear regression relation. Based on the $95 \%$ confidence interval of the datasets, the mean value of regression equations was obtained. There were 90 sets of overall data having the magnitude $\mathrm{M}_{\mathrm{w}}$ and $\mathrm{M}_{\mathrm{b}}$, five sets of overall data found for $M_{w}$ and $M_{L}$, and also 86 sets of overall data having $\mathrm{M}_{\mathrm{w}}$ and $\mathrm{M}_{\mathrm{s}}$. The developed correlations are shown in figure 2 . All the collected events were homogenized accordingly based
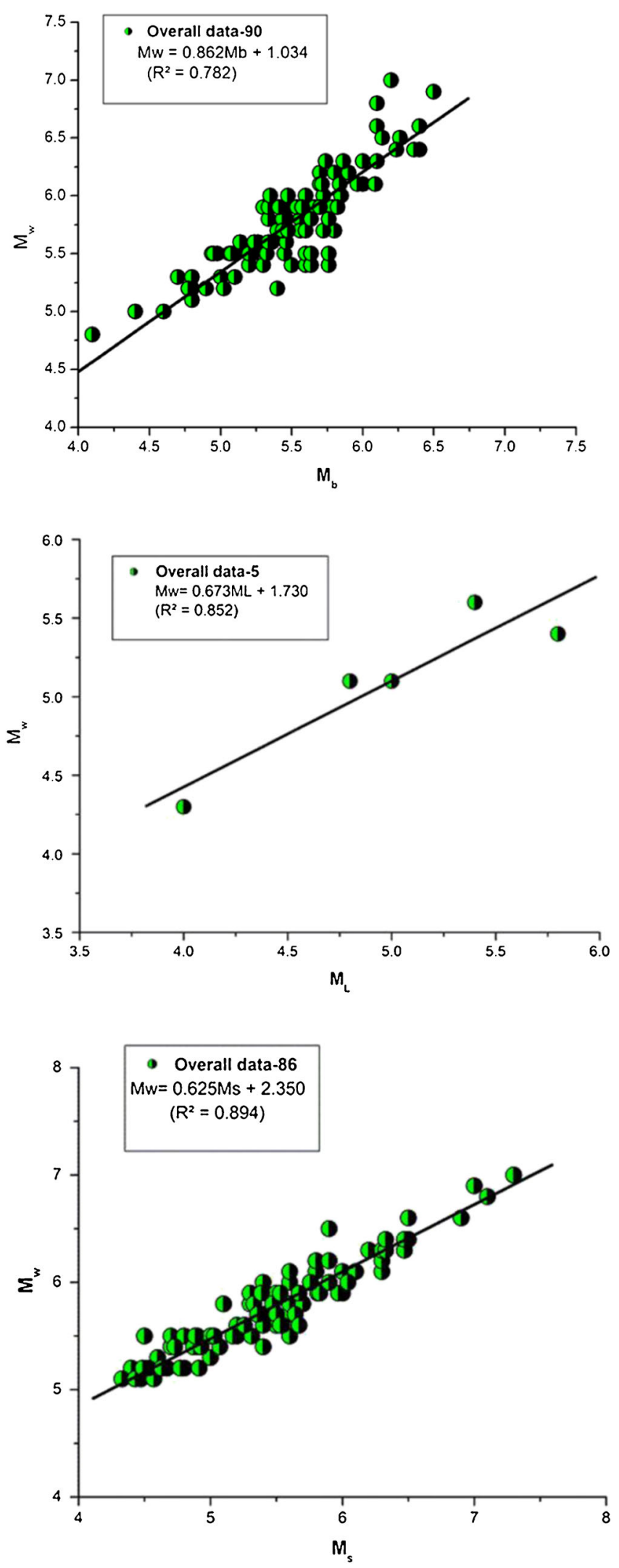

Figure 2. Correlations between various magnitude scales $\left(\mathrm{M}_{\mathrm{w}}\right.$ with $\mathrm{M}_{\mathrm{b}}, \mathrm{M}_{\mathrm{L}}$ and $\left.\mathrm{M}_{\mathrm{S}}\right)$ considering the available data of the region (in and around NE India) since 1731-2011. 
on these correlations and used for further study. Indeed, pre-instrumental earthquake catalogue was homogenized by following the intensity scale. Most of the researchers considered the reported intensity as Modified Mercalli Intensity (MMI) scale and used Guttenberg Richter empirical relation to convert $\mathrm{MMI}$ to $\mathrm{M}_{\mathrm{w}}$ as given in equation $\left(\mathrm{M}_{\mathrm{w}}=\right.$ $2 / 3 \mathrm{MMI}+1)$. The number of major earthquakes $\left(\mathrm{M}_{\mathrm{w}}>7.0\right)$ catalogue covering the study area since 1731 to 2011 are shown in table 2.

\subsection{Seismic source zones}

In northeast India, a complex seismotectonic setting is observed such as plate boundary activity in northern Himalaya, intraplate activity in Shillong Plateau, and subduction process in east (Indo-Burma range). In the present study, identified earthquake events (main shocks) were superimposed on the digitized tectonic map (SEISAT 2000) to look for the connectivity between the seismic events and identified faults are shown in figure 3 . We have used similar approaches suggested by Kayal (1998) and Gupta (2006) to characterize the seismic source zones in northeast India. However, Kayal (1998) divided the region into five zones based on seismicity (data used 1964-1996) and epicentral depth. Gupta (2006), has also divided the region (northeast India) into a number of smaller seismic sources (19 zones) based on tectonic features, source mechanism, and seismicity characteristics. In the present study, we identified six major potential seismic source zones in and around the study area considering seismic event distribution pattern and the orientation of all sources or faults which are shown in figure 4 . The characterized potential seismic source zones are EH, IBR, SP, Naga Thrust (NT), Mishmi Thrust (MT), and Bengal Basin (BB), respectively. The catalogue has been separated for each source zone for estimation of seismicity parameters. This region has been divided into six major seismic source zones, where out of 3251 collected events as main shocks, 1709 events were found for IBR, 514 events were found for EH, 263 events for SP, and 205 events for BB, 252 events for NT, and 142 events for MT. A total of 166 scattered events were outside the newly proposed source zones and hence were not taken into account for further study.

\subsection{Catalogue completeness}

In 1972, Steep proposed a method based on the length of the period over which a particular magnitude is complete. In this method, catalogues are grouped into several magnitude ranges and each magnitude range is considered as a point process in time. The magnitude of completeness is the lowest magnitude above which the earthquake recording is assumed to be complete (Rydelek and Sacks 1989).

As a first step for the evaluation of the completeness period, the number of earthquakes reported during each decade for the given magnitude ranges

Table 2. Details of major earthquakes $\left(M_{\mathrm{w}}>7.0\right)$ in and around study area (NE India) in recent past.

\begin{tabular}{lrrrrr}
\hline Longitude $\left(^{\circ}\right)$ & Latitude $\left(^{\circ}\right)$ & Year & Month & Date & $\mathrm{M}_{\mathrm{w}}$ \\
\hline 88.40 & 22.60 & 1737 & 5 & 11 & 7.7 \\
86.50 & 27.50 & 1833 & 8 & 26 & 8.0 \\
96.00 & 22.00 & 1839 & 3 & 23 & 7.1 \\
90.00 & 25.00 & 1842 & 11 & 11 & 7.0 \\
91.50 & 24.50 & 1868 & 6 & 30 & 7.5 \\
91.00 & 26.00 & 1897 & 6 & 12 & 8.1 \\
97.00 & 27.00 & 1906 & 8 & 31 & 7.1 \\
97.00 & 26.50 & 1908 & 12 & 12 & 8.2 \\
91.00 & 24.50 & 1918 & 7 & 8 & 7.6 \\
91.00 & 25.25 & 1923 & 9 & 9 & 7.2 \\
90.20 & 25.80 & 1930 & 7 & 2 & 7.2 \\
96.80 & 25.60 & 1931 & 1 & 27 & 7.6 \\
86.50 & 26.50 & 1934 & 1 & 15 & 8.1 \\
94.25 & 23.50 & 1938 & 8 & 16 & 7.3 \\
96.00 & 23.50 & 1946 & 9 & 12 & 7.5 \\
96.50 & 28.60 & 1950 & 8 & 15 & 8.6 \\
93.80 & 24.40 & 1957 & 7 & 1 & 7.3 \\
95.12 & 25.15 & 1988 & 8 & 6 & 7.4 \\
86.58 & 26.89 & 1988 & 8 & 20 & 7.3 \\
95.90 & 23.60 & 1991 & 1 & 5 & 7.4 \\
\hline
\end{tabular}




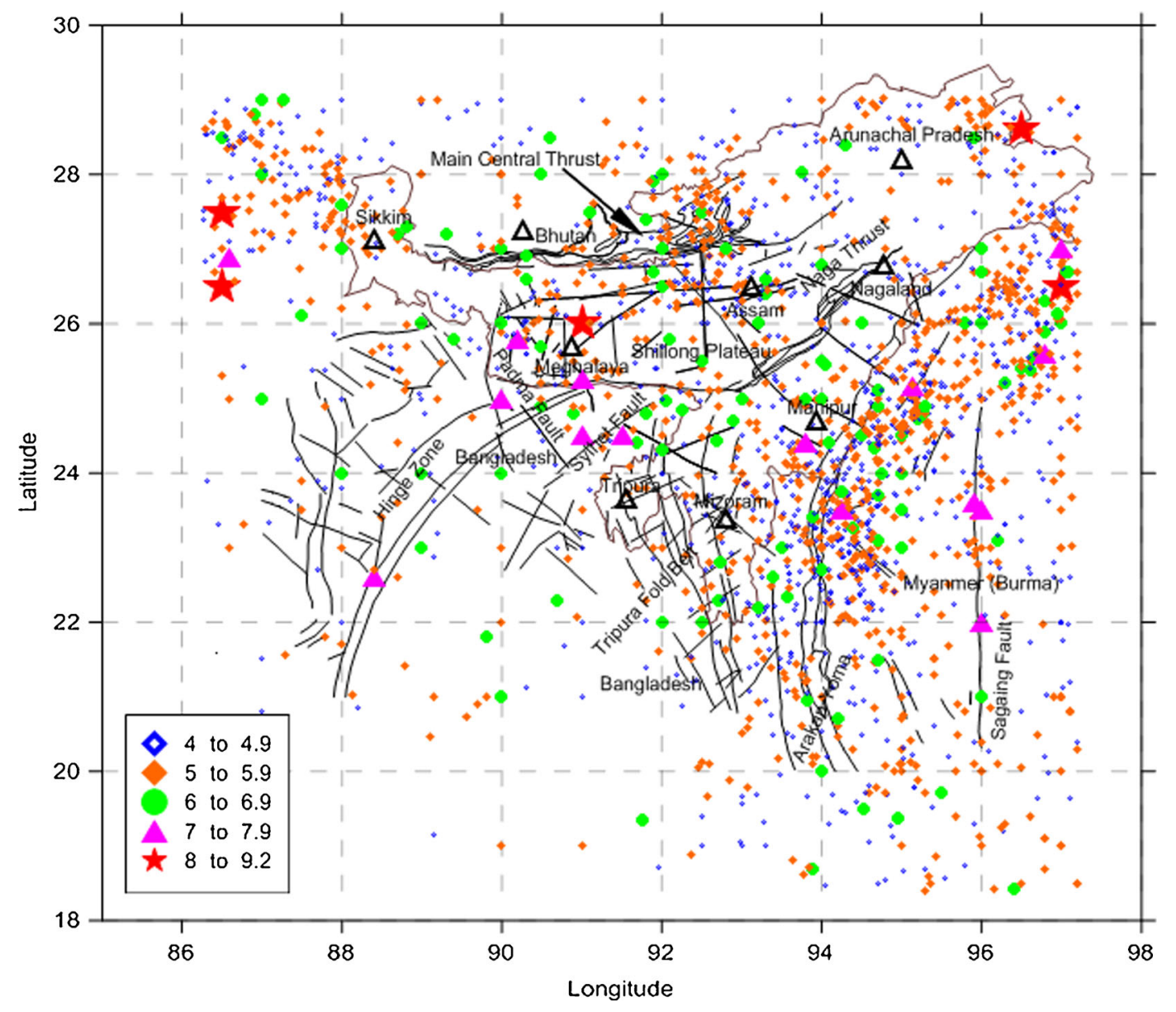

Figure 3. Seismotectonic map of the study area (NE India). (Geographical boundaries shown in the figure are approximate.)

were evaluated. The plot showing the variation of $\sigma_{\lambda}$ with time is given in figure 5 . The earthquake data is considered as complete as long as its variation is along the $1 / \sqrt{T}$ line. The plotted points are assumed to have a straight line following a slope as long as the data becomes complete. From figure 5, it is clear that the magnitude range $4-4.9$ is complete for 40 years, 5-5.9 is complete for 50 years, 6-6.9 is complete for 90 years, 7.9 is complete for 130 years and greater than 8 is complete for 200 years. Further, the completeness of the catalogue was also estimated based on the visual cumulative method (CUVI). In this method, the cumulative number of events per year is plotted against the period of occurrence in years for each size of magnitude range (figure 6). The completeness periods based on both the methods (Steep 1972 and CUVI) were presented in tabular form ( $\mathrm{t} 3.4$ table 3 ) and they compare very well.

\subsection{Seismicity parameter estimation}

The seismic activity of a region is described by two parameters which correlate between the magnitude and cumulative frequency or the rate of occurrences of a particular magnitude. Gutenberg and Richter (1944) developed a relationship which assumes an exponential distribution of magnitude and is expressed as:

$$
\log N=a-b M
$$

where ' $a$ (intercept)' and ' $b$ (slope)' are the constants of regression, which describe the seismicity of a region, $N$ is the mean annual rate of occurrence of a certain magnitude $\mathrm{M}_{\mathrm{w}}$ and above. These parameters are the key inputs in the probabilistic seismic hazard assessment (PSHA). Higher $a, b$ values indicate a higher level of seismicity ( $a$-value) with a larger proportion of smaller size events $(b-$ value) or in other words, the $b$-value describes the relative size distribution of events. Indeed, the importance of $b$-value is such that, a small change in $b$-value results in large changes in the projected number of major earthquakes and also indicates an asperity level of constituents of the underlying rock mass. In this study, the catalogue is segregated for each source zone respectively and seismicity parameters ( $a, b$ values) are evaluated using $\mathrm{G}-\mathrm{R}$ relationship. The estimated seismicity parameters are presented in table 4. 


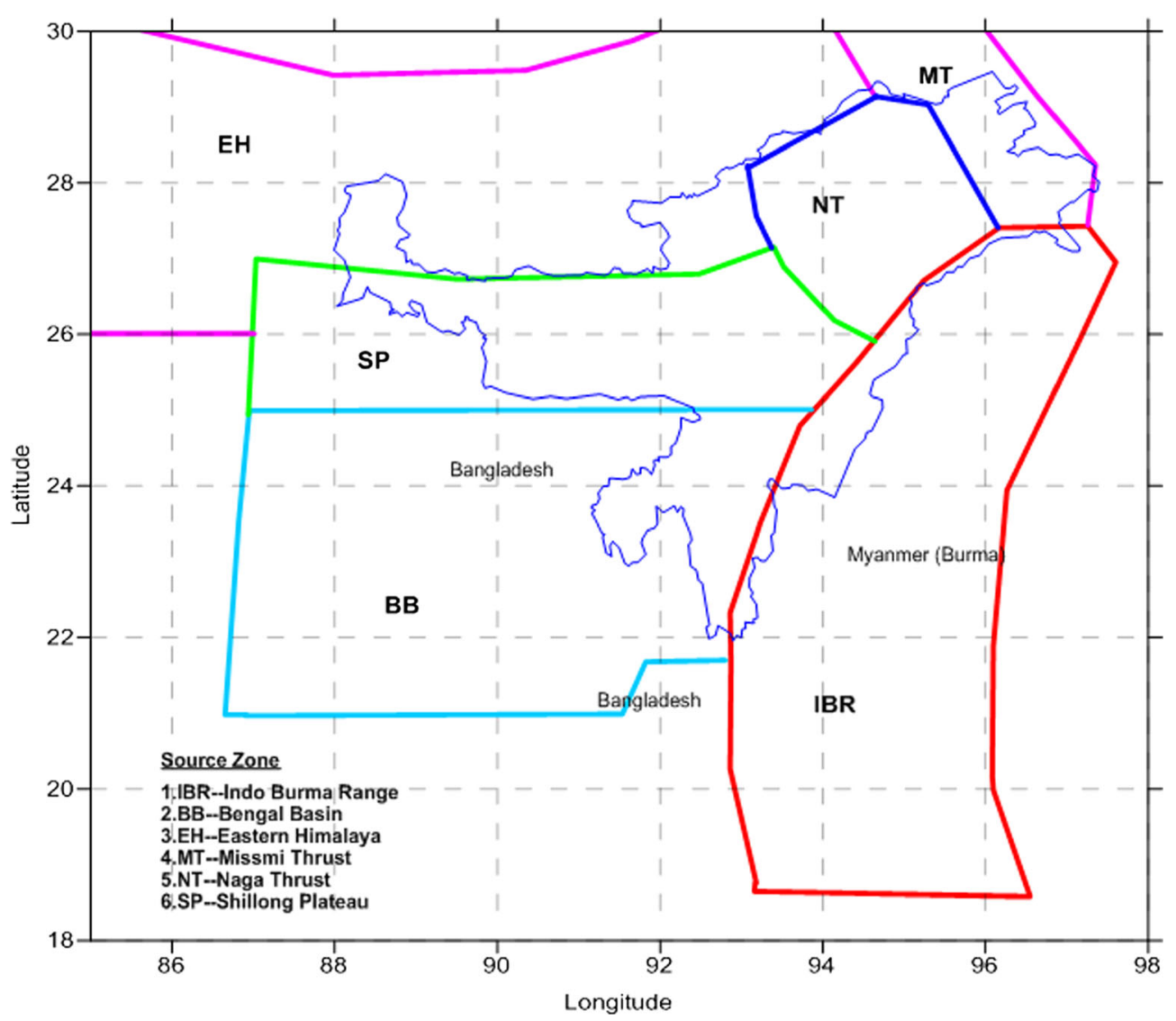

Figure 4. Seismic source zones of the study area. (Geographical boundaries shown in the figure are approximate.)

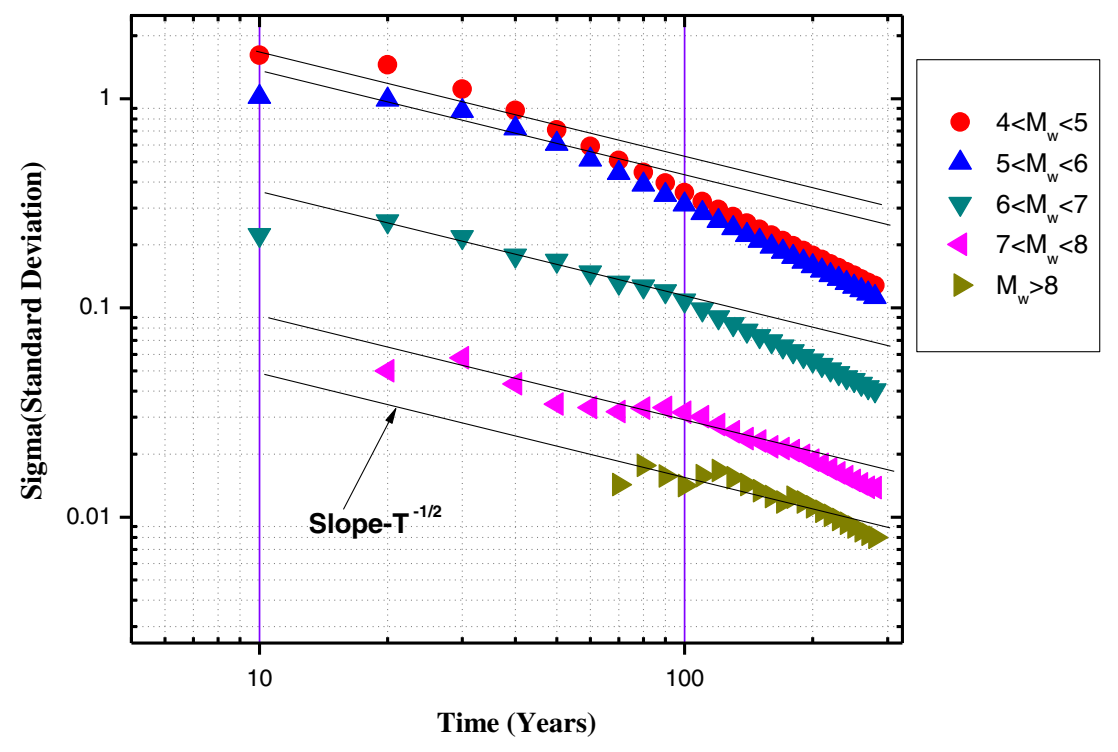

Figure 5. Catalogue completeness analysis using Steep (1972).

\subsection{Ground motion predictive equations}

The ground motion model is generally developed based on the region specific manner considering the tectonic features (plate boundary, subduction, and intraplate), after collecting the available information regarding the accelerogram records in different distances with different magnitudes throughout the study area/region, a regression analysis is carried out based on different PGA values considering the distances and magnitudes to get the mean value of acceleration with minimum 

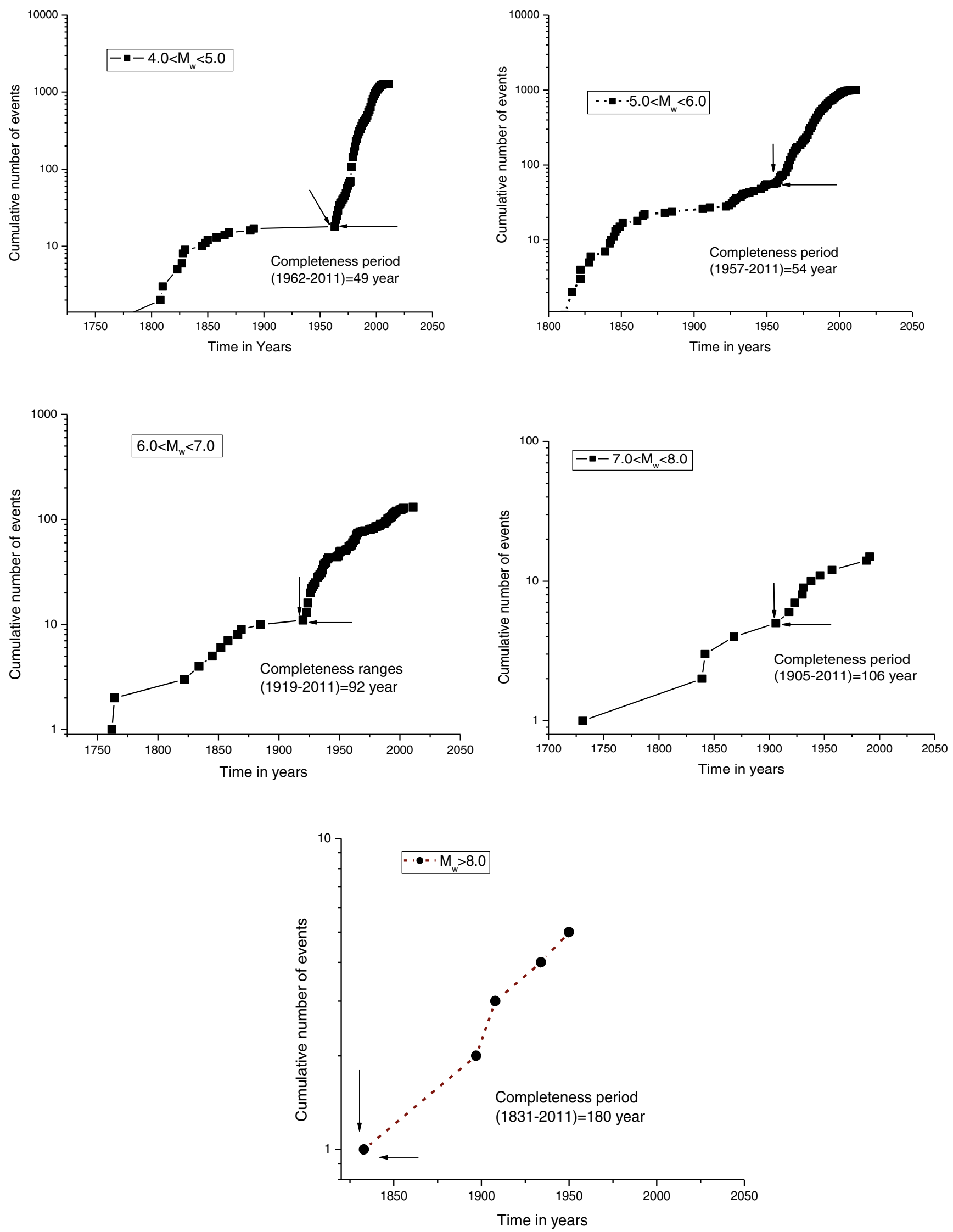

Figure 6. Completeness analysis of catalogue based on CUVI method. 
Table 3. Completeness period of catalogue based on Steep (1972) and CUVI methods.

\begin{tabular}{lcc}
\hline \multirow{2}{*}{ Magnitude interval } & \multicolumn{2}{c}{ Completeness period (years) } \\
\cline { 2 - 3 } & \multicolumn{1}{c}{ CUVI method } & Steep method $(1972)$ \\
\hline $4.0<\mathrm{M}_{\mathrm{W}}<4.9$ & $1962-2011=49$ & $1971-2011=40$ \\
$5<\mathrm{M}_{\mathrm{W}}<5.9$ & $1957-2011=54$ & $1961-2011=50$ \\
$6<\mathrm{M}_{\mathrm{W}}<6.9$ & $1919-2011=92$ & $1921-2011=90$ \\
$7<\mathrm{M}_{\mathrm{W}}<7.9$ & $1905-2011=106$ & $1881-2011=130$ \\
$\mathrm{M}_{\mathrm{w}}>8.0$ & $1831-2011=180$ & $1811-2011=200$ \\
\hline
\end{tabular}

Table 4. Seismicity parameters calculated for each zone.

\begin{tabular}{|c|c|c|c|c|c|}
\hline \multirow[b]{2}{*}{ Sl. no. } & \multirow[b]{2}{*}{ Seismic regions/zones } & \multicolumn{2}{|c|}{ Parameter } & \multirow[b]{2}{*}{$R^{2}$} & \multirow{2}{*}{$\begin{array}{l}\text { No. of events } \\
\text { zone till } 2011\end{array}$} \\
\hline & & $a$ value & $b$ value & & \\
\hline 1 & Indo-Burma Range (IBR) & 4.946 & 0.798 & 0.960 & 1282 \\
\hline 2 & Eastern Himalaya (EH) & 4.878 & 0.867 & 0.923 & 152 \\
\hline 3 & Shillong Plateau (SP) & 3.289 & 0.613 & 0.984 & 218 \\
\hline 4 & Bengal Basin (BB) & 3.038 & 0.613 & 0.933 & 395 \\
\hline 5 & Naga Thrust (NT) & 2.576 & 0.546 & 0.943 & 99 \\
\hline 6 & Mishmi Thrust (MT) & 2.544 & 0.542 & 0.902 & 114 \\
\hline
\end{tabular}

$R^{2}$ - coefficient of correlation between magnitude $\left(\mathrm{M}_{\mathrm{W}}\right)$ and rate of occurrence.

variances and then coefficients are calculated for different periods for ready references of that region. Based on the seismicity and different tectonic activities of this region, the area is divided into two categories: shallow crustal intraplate/interplate tectonic and subduction inslab/interface zone. Therefore, different attenuation relations should be used for this region. In India, there is scarcity of strong motion data and this in turn has resulted in the development of only very few region-specific attenuation relations. Since, only a few attenuation relations were available for the study area, in the present study we have used Gupta (2010) which was developed mainly in the northeast region of India and well accepted ground motion model (Atkinson and Boore 2003), which was developed using the global database for subduction zone.

However, lack of recorded strong motion data at different distances makes the attenuation models inefficient to predict the future ground motion especially at large distances. The strong motion data have been collected from 'Cosmos virtual data center' (http://db.cosmos-eq.org/) to validate the selected attenuation relationship for this region. Based on seven earthquakes during 1987-1997, the data recorded in different stations using digital network (SMART-1) for Indo-Burma range and northeast India have been used, to validate the prediction equations. Only rock level recorded PGAs have been used, which is shown in figure 7. The prediction equation given by Gupta (2010) and

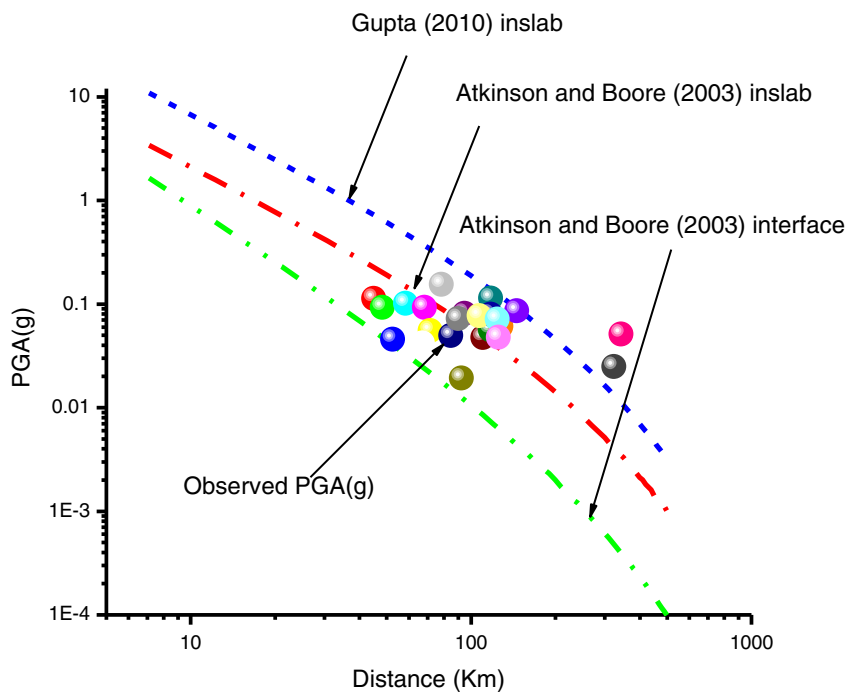

Figure 7. Validation of attenuation equations using avaiable strong motion data $\left(\mathrm{M}_{\mathrm{w}}\right.$ 5.9) for subduction earthquakes (since 1986, 1988 and 1990-1997) in northeast India.

Atkinson and Boore (2003) is shown up to the bedrock level condition.

$$
\log \mathrm{Y}=\mathrm{C}_{1}+\mathrm{C}_{2} \mathrm{M}_{\mathrm{w}}+\mathrm{C}_{3} \mathrm{~h}+\mathrm{C}_{4} \mathrm{R}-\mathrm{g} \log \mathrm{R}
$$

where Y represents mean PGA at bedrock level in $\mathrm{cm} / \mathrm{sec}^{2}, \mathrm{M}_{\mathrm{w}}$ the moment magnitude, ' $\mathrm{h}$ ' is the focal depth in ' $\mathrm{km}$ ', ' $\mathrm{R}$ ' is hypocentral distance in ' $\mathrm{km}$ ', and ' $\mathrm{g}$ ' is the geometric attenuation 
parameter. The source/focal depths were estimated from the catalogue (1731-2011) collected for the present study. The summary of source/focal depth (average) estimated was used for hazard assessment in various proposed seismic source zones in the study region such as $\mathrm{EH}(39 \mathrm{~km}), \mathrm{SP}(37 \mathrm{~km})$, IBR $(66 \mathrm{~km})$, NT $(66 \mathrm{~km}), \mathrm{MT}(31 \mathrm{~km})$ and BB $(31 \mathrm{~km})$.

It is observed that the Gupta inslab attenuation model (Gupta 2010) overestimates the PGA at short distances but slightly underestimates at large distances. Atkinson and Boore (2003) inslab attenuation relation predict median values with the observed PGAs at short distances. However, these models completely underestimate the PGA values at larger distances. The validation of ground motion models confirms their applicability/predictability and helps in selecting the best model fitted for the region of use which is up to $100-130 \mathrm{~km}$ range from the source in the present study. As per recent seismic regulatory guidelines (NDMA 2010, India), any potential seismic source can hit or contribute hazard up to $300 \mathrm{~km}$ distance. However, the seismic regulatory committee emphasized for seismically more active regions (like Himalayan belt, whole northeast India) to use distance up to $500 \mathrm{~km}$ from the source. Therefore, a new GMPE is required to be developed for accurate estimation of hazard at larger distances. More, regions recorded strong motion data specifically for large distances are required from the network of seismic array available in northeast India and adjoining areas for this purpose.

\subsection{Estimation of maximum magnitude $\left(M_{\max }\right)$}

In seismic hazard analysis, the knowledge of estimating the maximum magnitude is important and used as one of the key input parameters in the seismic design. It indicates the highest potential of accumulated strain energy to be released in the region or a seismic source/fault. Alternatively, the $\mathrm{M}_{\max }$ is an upper limit or the largest possible earthquake that may produce the highest seismic hazard scenarios of the region. However, in the study region, very limited amount of data is available for the last few decades (based on the instrumental recorded data, since 1964), which do not sufficiently reveal the full seismic potential characteristics of any seismic source/fault with confidence. Further, there is no well known or well defined methodology available for evaluation of maximum magnitude. Some of the methods have been proposed by various researchers such as Kijko and Sellevol (1989), Wells and Coppersmith (1994), Gupta (2002), and Mueller (2010). In the present work, $\mathrm{M}_{\max }$ is estimated considering three approaches. These are Kijko and Sellevol (1989) method, by adding incremental values (Gupta 2002) and using fault rupture relationship (Wells and Coppersmith 1994).

Method-A: To determine the maximum magnitude of a fault or source, Wells and Coppersmith (1994) proposed some empirical equations based on the subsurface fault rupture characteristics such as length, area and slip rate of the fault with the moment magnitude. These empirical equations were developed by standard statistical regression using a global database of the events. These relations are given based on tectonic regime characteristics such as strike-slip, reverse, and normal faulting and also the average relation for all slip types are developed to be appropriate for most applications in general (if the fault type is unknown). In this work, the length of faults was estimated from the seismotectonic atlas (SEISAT-2000) of India published by GSI (Geological Survey of India) and some of the faults were extracted from the literature. All these faults/lineaments were digitized using Mapinfo software version 10 and the length of the respective faults evaluated. The relation proposed by Wells and Coppersmith (1994) to estimate expected moment magnitude of a linear fault is given below:

$$
\log (\mathrm{SRL})=0.57 \mathrm{M}_{\mathrm{w}}-2.33 \text {. }
$$

The relation between $M_{w}$ and surface rupture length (SRL) was developed using reliable source parameters and this is applicable for all types of faults, shallow earthquakes, and interplate or intraplate earthquakes (Wells and Coppersmith 1994). Using this equation along with a parametric study, it is observed that the subsurface fault rupture length of about $3.8 \%$ of the total fault length provides moment magnitude values closely matching those of the past earthquakes. The estimation procedure is presented in tabular form (method-A) in table 5 .

Method-B (by adding incremental value): This method has been proposed by Gupta (2002) after adding an incremental unit. In this method to estimate $\mathrm{M}_{\max }$ an increment of 0.5 is added to the observed maximum magnitude. This approach is simple and provides unarguable lower limit for $\mathrm{M}_{\max }$ (Wheeler 2009). This incremental technique has been used by various researchers to estimate the seismic hazard in India (Jaiswal and Sinha 2007a, b, 2008; Menon et al. 2010; NDMA 2010; Roshan and Basu 2010; Boominathan 2011; Sitharam and Vipin 2011; Kolathayar and Sitharam 2012). 
Table 5. Estimation of maximum magnitude for faults/lineaments of the study area.

\begin{tabular}{|c|c|c|c|c|c|c|c|c|c|c|c|}
\hline \multirow[b]{3}{*}{ Sl. no. } & & & & & \multirow{3}{*}{$\begin{array}{c}\mathrm{M}_{\mathrm{w}} \\
\text { observed } \\
\text { in the } \\
\text { fault }\end{array}$} & \multicolumn{3}{|c|}{ Method-A } & \multirow{3}{*}{$\begin{array}{c}\text { Method-B } \\
\mathrm{M}_{\max }, \text { by } \\
\text { incremental } \\
\text { value } \\
\text { (Gupta 2002) }\end{array}$} & \multirow{3}{*}{$\begin{array}{c}\text { Method-C } \\
\text { (Kijko } \\
\text { and Sellevol } \\
\text { 1989) }\end{array}$} & \multirow{3}{*}{$\begin{array}{l}\mathrm{M}_{\max } \\
\text { considered } \\
\text { for the } \\
\text { present } \\
\text { study }\end{array}$} \\
\hline & \multicolumn{4}{|c|}{ Fault coordinates } & & $\begin{array}{l}\text { Length } \\
\text { of fault } \\
\text { (TFL) }\end{array}$ & $\begin{array}{c}\text { SRL } \\
3.8 \% \text { of } \\
\text { TFL }\end{array}$ & & & & \\
\hline & Lat. & Long. & Lat. & Long. & & $(\mathrm{km})$ & $(\mathrm{km})$ & $\mathrm{M}_{\max }$ & & & \\
\hline 1 & 20.34 & 95.98 & 21.61 & 95.98 & 5.5 & 141.402 & 5.37326 & 5.4 & 6.0 & 5.5 & 6.0 \\
\hline 2 & 21.61 & 95.92 & 23.17 & 95.98 & 7.4 & 173.777 & 6.60352 & 5.5 & 7.9 & 8.2 & 8.2 \\
\hline 3 & 23.16 & 95.91 & 24.83 & 95.96 & 7.4 & 185.449 & 7.04708 & 5.6 & 7.9 & 8.2 & 8.2 \\
\hline 4 & 24.00 & 95.28 & 24.57 & 95.52 & 5.5 & 68.7746 & 2.61343 & 4.8 & 6.0 & 5.5 & 6.0 \\
\hline 5 & 24.00 & 95.14 & 24.24 & 95.22 & 4.5 & 27.1705 & 1.03247 & 4.1 & 5.0 & 4.5 & 5.0 \\
\hline 6 & 24.39 & 95.28 & 24.55 & 95.41 & 5.5 & 22.9433 & 0.87184 & 4.0 & 6.0 & 5.5 & 6.0 \\
\hline 7 & 20.90 & 95.86 & 21.06 & 95.86 & 5.5 & 8320.64 & 316.184 & 8.5 & 6.0 & 5.5 & 8.5 \\
\hline 8 & 20.82 & 94.89 & 21.49 & 95.19 & 4.7 & 82.1592 & 3.12205 & 5.0 & 5.2 & 4.7 & 5.2 \\
\hline 9 & 20.71 & 94.77 & 21.53 & 95.06 & 6.6 & 96.4513 & 3.66515 & 5.1 & 7.1 & 6.6 & 7.1 \\
\hline 10 & 20.01 & 94.01 & 21.13 & 94.49 & 5.5 & 135.035 & 5.13135 & 5.3 & 6.0 & 5.5 & 6.0 \\
\hline 11 & 21.13 & 94.01 & 21.62 & 94.05 & 4.7 & 54.7597 & 2.08087 & 4.6 & 5.2 & 4.7 & 5.2 \\
\hline 12 & 21.64 & 94.02 & 22.49 & 94.03 & 5.5 & 94.8420 & 3.60399 & 5.1 & 6.0 & 5.5 & 6.0 \\
\hline 13 & 22.51 & 94.01 & 23.58 & 94.03 & 6.5 & 118.316 & 4.49601 & 5.2 & 7.0 & 6.5 & 7.0 \\
\hline 14 & 23.58 & 94.04 & 23.99 & 94.26 & 5.5 & 51.6035 & 1.96093 & 4.6 & 6.0 & 5.5 & 6.0 \\
\hline 15 & 24.03 & 94.19 & 25.45 & 94.99 & 6.5 & 181.432 & 6.89442 & 5.6 & 7.0 & 6.5 & 7.0 \\
\hline 16 & 25.40 & 95.06 & 26.58 & 96.02 & 5.5 & 168.716 & 6.41122 & 5.5 & 6.0 & 5.5 & 6.0 \\
\hline 17 & 20.22 & 93.74 & 21.12 & 94.10 & 6.7 & 107.246 & 4.07535 & 5.2 & 7.2 & 6.7 & 7.2 \\
\hline 18 & 21.12 & 93.73 & 22.44 & 93.79 & 6.5 & 146.509 & 5.56734 & 5.4 & 7.0 & 6.5 & 7.0 \\
\hline 19 & 22.44 & 93.79 & 22.70 & 93.94 & 5.5 & 33.7312 & 1.28178 & 4.3 & 6.0 & 5.5 & 6.0 \\
\hline 20 & 22.70 & 93.79 & 23.13 & 93.94 & 5.5 & 50.1397 & 1.90530 & 4.6 & 6.0 & 5.5 & 6.0 \\
\hline 21 & 23.13 & 93.79 & 24.00 & 93.96 & 6.7 & 98.1421 & 3.72940 & 5.1 & 7.2 & 6.7 & 7.2 \\
\hline 22 & 24.09 & 24.00 & 24.75 & 94.41 & 6.5 & 7816.33 & 297.020 & 8.4 & 7.0 & 6.5 & 8.4 \\
\hline 23 & 24.62 & 93.85 & 25.00 & 94.52 & 6.5 & 85.6075 & 3.25308 & 5.0 & 7.0 & 6.5 & 7.0 \\
\hline 24 & 24.36 & 93.52 & 24.63 & 93.99 & 7.4 & 60.1688 & 2.28641 & 4.7 & 7.9 & 8.2 & 8.2 \\
\hline 25 & 24.74 & 94.41 & 25.09 & 94.44 & 5.5 & 38.8997 & 1.47818 & 4.4 & 6.0 & 5.5 & 6.0 \\
\hline 26 & 24.85 & 94.96 & 25.89 & 95.59 & 7.4 & 135.319 & 5.14214 & 5.3 & 7.9 & 8.2 & 8.2 \\
\hline 27 & 25.09 & 94.44 & 26.35 & 95.29 & 5.5 & 168.835 & 6.41573 & 5.5 & 6.0 & 5.5 & 6.0 \\
\hline 28 & 26.35 & 95.29 & 27.07 & 96.02 & 6.5 & 114.078 & 4.33499 & 5.2 & 7.0 & 6.5 & 7.0 \\
\hline 29 & 26.04 & 95.10 & 26.68 & 95.26 & 5.5 & 73.4787 & 2.79219 & 4.9 & 6.0 & 5.5 & 6.0 \\
\hline 30 & 26.25 & 95.59 & 26.47 & 95.68 & 5.5 & 26.2833 & 0.99876 & 4.1 & 6.0 & 5.5 & 6.0 \\
\hline 31 & 26.51 & 95.81 & 26.96 & 95.94 & 6.5 & 51.6807 & 1.96387 & 4.6 & 7.0 & 6.5 & 7.0 \\
\hline 32 & 25.20 & 93.99 & 25.95 & 94.96 & 5.5 & 135.873 & 5.16318 & 5.3 & 6.0 & 5.5 & 6.0 \\
\hline 33 & 20.03 & 93.50 & 20.60 & 93.68 & 5.5 & 66.7718 & 2.53733 & 4.8 & 6.0 & 5.5 & 6.0 \\
\hline 34 & 20.60 & 93.43 & 21.82 & 93.50 & 5.5 & 135.933 & 5.16546 & 5.3 & 6.0 & 5.5 & 6.0 \\
\hline 35 & 21.82 & 93.38 & 22.22 & 93.43 & 5.5 & 43.8924 & 1.66791 & 4.5 & 6.0 & 5.5 & 6.0 \\
\hline 36 & 22.21 & 93.37 & 22.67 & 93.39 & 6.5 & 50.5830 & 1.92215 & 4.6 & 7.0 & 6.5 & 7.0 \\
\hline 37 & 21.00 & 92.96 & 21.68 & 93.47 & 5.5 & 94.2507 & 3.58152 & 5.1 & 6.0 & 5.5 & 6.0 \\
\hline 38 & 20.79 & 92.73 & 21.76 & 92.95 & 5.5 & 110.362 & 4.19375 & 5.2 & 6.0 & 5.5 & 6.0 \\
\hline 39 & 21.24 & 92.84 & 21.76 & 92.98 & 5.5 & 59.4872 & 2.26051 & 4.7 & 6.0 & 5.5 & 6.0 \\
\hline 40 & 21.76 & 92.83 & 22.34 & 92.84 & 5.7 & 65.0498 & 2.47189 & 4.8 & 6.2 & 5.7 & 6.2 \\
\hline 41 & 22.34 & 92.75 & 22.66 & 92.83 & 4.7 & 35.7314 & 1.35779 & 4.3 & 5.2 & 4.7 & 5.2 \\
\hline 42 & 21.23 & 92.17 & 21.55 & 92.32 & 4.8 & 39.3219 & 1.49423 & 4.4 & 5.3 & 4.8 & 5.3 \\
\hline 43 & 20.86 & 92.15 & 21.85 & 92.67 & 5.5 & 124.992 & 4.74970 & 5.3 & 6.0 & 5.5 & 6.0 \\
\hline 44 & 20.83 & 92.62 & 21.60 & 92.85 & 4.3 & 89.3190 & 3.39412 & 5.0 & 4.8 & 4.3 & 5.0 \\
\hline 45 & 21.59 & 92.59 & 21.96 & 92.62 & 6.7 & 41.2626 & 1.56798 & 4.4 & 7.2 & 6.7 & 7.2 \\
\hline 46 & 21.52 & 92.28 & 21.98 & 92.74 & 5.5 & 72.1909 & 2.74325 & 4.9 & 6.0 & 5.5 & 6.0 \\
\hline 47 & 21.96 & 92.36 & 22.55 & 92.59 & 5.5 & 70.0122 & 2.66046 & 4.8 & 6.0 & 5.5 & 6.0 \\
\hline 48 & 22.55 & 92.05 & 23.04 & 92.36 & 5.5 & 64.4264 & 2.44820 & 4.8 & 6.0 & 5.5 & 6.0 \\
\hline 49 & 23.04 & 92.03 & 23.36 & 92.05 & 4.5 & 35.1588 & 1.33603 & 4.3 & 5.0 & 4.5 & 5.0 \\
\hline 50 & 22.51 & 91.57 & 23.40 & 92.16 & 5.5 & 118.070 & 4.48667 & 5.2 & 6.0 & 5.5 & 6.0 \\
\hline 51 & 23.40 & 91.43 & 23.99 & 91.57 & 5.5 & 67.9087 & 2.58053 & 4.8 & 6.0 & 5.5 & 6.0 \\
\hline
\end{tabular}


Table 5. (Continued.)

\begin{tabular}{|c|c|c|c|c|c|c|c|c|c|c|c|}
\hline \multirow[b]{3}{*}{ Sl. no. } & & & & & \multirow{3}{*}{$\begin{array}{c}\mathrm{M}_{\mathrm{w}} \\
\text { observed } \\
\text { in the } \\
\text { fault }\end{array}$} & \multicolumn{3}{|c|}{ Method-A } & \multirow{3}{*}{$\begin{array}{c}\text { Method-B } \\
\mathrm{M}_{\max }, \text { by } \\
\text { incremental } \\
\text { value } \\
\text { (Gupta 2002) }\end{array}$} & \multirow{3}{*}{$\begin{array}{l}\text { Method-C } \\
\quad \text { (Kijko } \\
\text { and Sellevol } \\
\quad 1989)\end{array}$} & \multirow{3}{*}{$\begin{array}{c}\mathrm{M}_{\max } \\
\text { considered } \\
\text { for the } \\
\text { present } \\
\text { study }\end{array}$} \\
\hline & \multicolumn{4}{|c|}{ Fault coordinates } & & $\begin{array}{l}\text { Length } \\
\text { of fault } \\
\text { (TFL) }\end{array}$ & $\begin{array}{c}\text { SRL } \\
3.8 \% \text { of } \\
\text { TFL }\end{array}$ & & & & \\
\hline & Lat. & Long. & Lat. & Long. & & $(\mathrm{km})$ & $(\mathrm{km})$ & $\mathrm{M}_{\max }$ & & & \\
\hline 52 & 24.00 & 92.03 & 24.48 & 92.05 & 6.5 & 53.5566 & 2.03515 & 4.6 & 7.0 & 6.5 & 7.0 \\
\hline 53 & 24.26 & 92.05 & 24.61 & 92.89 & 6.7 & 101.149 & 3.84367 & 5.1 & 7.2 & 6.7 & 7.2 \\
\hline 54 & 22.63 & 92.56 & 23.48 & 92.82 & 6.6 & 98.361 & 3.73771 & 5.1 & 7.1 & 6.6 & 7.1 \\
\hline 55 & 22.60 & 92.49 & 22.97 & 92.98 & 5.5 & 68.3879 & 2.59874 & 4.8 & 6.0 & 5.5 & 6.0 \\
\hline 56 & 22.06 & 92.33 & 22.50 & 92.97 & 6.5 & 86.0728 & 3.27076 & 5.0 & 7.0 & 6.5 & 7.0 \\
\hline 57 & 22.90 & 93.42 & 23.66 & 92.53 & 6.5 & 130.494 & 4.95880 & 5.3 & 7.0 & 6.5 & 7.0 \\
\hline 58 & 23.57 & 92.51 & 24.05 & 92.54 & 5.7 & 53.9757 & 2.05107 & 4.6 & 6.2 & 5.7 & 6.2 \\
\hline 59 & 24.05 & 92.51 & 92.65 & 92.65 & 5.6 & 7614.08 & 289.335 & 8.4 & 6.1 & 5.6 & 8.4 \\
\hline 60 & 24.00 & 92.88 & 24.47 & 92.96 & 5.5 & 53.2848 & 2.02482 & 4.6 & 6.0 & 5.5 & 6.0 \\
\hline 61 & 23.20 & 92.56 & 23.93 & 92.99 & 5.5 & 93.9751 & 3.57105 & 5.1 & 6.0 & 5.5 & 6.0 \\
\hline 62 & 24.00 & 91.83 & 24.38 & 91.89 & 4.5 & 43.0722 & 1.63674 & 4.5 & 5.0 & 4.5 & 5.0 \\
\hline 63 & 24.00 & 91.53 & 24.65 & 92.68 & 7.4 & 146.335 & 5.56075 & 5.4 & 7.9 & 8.2 & 8.2 \\
\hline 64 & 23.51 & 94.31 & 23.58 & 94.53 & 7.4 & 25.4410 & 0.96676 & 4.1 & 7.9 & 6 & 7.9 \\
\hline 65 & 22.63 & 94.36 & 23.11 & 94.92 & 5.7 & 81.2596 & 3.08786 & 4.9 & 6.2 & 5.7 & 6.2 \\
\hline 66 & 22.60 & 94.37 & 23.04 & 94.86 & 5.7 & 72.7373 & 2.76401 & 4.9 & 6.2 & 5.7 & 6.2 \\
\hline 67 & 22.45 & 91.56 & 22.86 & 91.77 & 5.5 & 51.1693 & 1.94443 & 4.6 & 6.0 & 5.5 & 6.0 \\
\hline 68 & 23.53 & 91.37 & 23.94 & 92.27 & 5.5 & 109.426 & 4.15819 & 5.2 & 6.0 & 5.5 & 6.0 \\
\hline 69 & 22.73 & 92.08 & 23.99 & 92.39 & 5.5 & 144.740 & 5.50014 & 5.4 & 6.0 & 5.5 & 6.0 \\
\hline 70 & 22.38 & 90.56 & 22.99 & 91.18 & 5.5 & 96.3038 & 3.65954 & 5.1 & 6.0 & 5.5 & 6.0 \\
\hline 71 & 23.11 & 90.32 & 23.74 & 90.99 & 4.5 & 102.808 & 3.90672 & 5.1 & 5.0 & 4.5 & 5.1 \\
\hline 72 & 23.30 & 90.78 & 23.63 & 90.90 & 5.5 & 39.1612 & 1.48812 & 4.4 & 6.0 & 5.5 & 6.0 \\
\hline 73 & 23.14 & 90.91 & 23.25 & 91.14 & 4.3 & 28.8378 & 1.09583 & 4.2 & 4.8 & 4.3 & 4.8 \\
\hline 74 & 23.00 & 90.97 & 23.19 & 90.71 & 4.5 & 35.6140 & 1.35333 & 4.3 & 4.5 & 4.5 & 5.0 \\
\hline 75 & 23.19 & 90.72 & 22.73 & 90.24 & 4.6 & 74.0134 & 2.81251 & 4.9 & 4.6 & 4.6 & 5.1 \\
\hline 76 & 22.69 & 90.03 & 23.77 & 90.57 & 5.7 & 133.483 & 5.07235 & 5.3 & 5.7 & 5.7 & 6.2 \\
\hline 77 & 23.31 & 89.39 & 23.71 & 89.84 & 5.7 & 66.4198 & 2.52395 & 4.8 & 5.7 & 5.7 & 6.2 \\
\hline 78 & 23.79 & 89.07 & 23.96 & 89.29 & 6.6 & 31.1755 & 1.18467 & 4.2 & 6.6 & 6.6 & 7.1 \\
\hline 79 & 21.04 & 88.03 & 22.29 & 88.41 & 5.5 & 145.837 & 5.54181 & 5.4 & 5.5 & 5.5 & 6.0 \\
\hline 80 & 22.29 & 88.41 & 22.82 & 88.68 & 5.7 & 65.7031 & 2.49672 & 4.8 & 5.7 & 5.7 & 6.2 \\
\hline 81 & 22.82 & 88.68 & 23.51 & 89.13 & 6.5 & 91.5092 & 3.47735 & 5.0 & 6.5 & 6.5 & 7.0 \\
\hline 82 & 23.51 & 89.13 & 24.40 & 89.99 & 4.5 & 137.261 & 5.21594 & 5.3 & 4.5 & 4.5 & 5.3 \\
\hline 83 & 24.02 & 89.93 & 24.54 & 90.14 & 6.5 & 62.0145 & 2.35655 & 4.7 & 6.5 & 6.5 & 7.0 \\
\hline 84 & 21.05 & 87.88 & 22.55 & 88.33 & 5.5 & 174.611 & 6.63522 & 5.5 & 5.5 & 5.5 & 6.0 \\
\hline 85 & 22.55 & 88.33 & 23.74 & 89.14 & 7.5 & 159.201 & 6.04965 & 5.5 & 7.5 & 7.6 & 8.0 \\
\hline 86 & 22.68 & 88.43 & 23.44 & 88.52 & 5.6 & 84.0476 & 3.19380 & 5.0 & 5.6 & 5.6 & 6.1 \\
\hline 87 & 22.68 & 88.03 & 22.94 & 88.32 & 5.3 & 43.8060 & 1.66463 & 4.5 & 5.3 & 5.3 & 5.8 \\
\hline 88 & 23.72 & 87.61 & 24.00 & 87.81 & 4.7 & 37.2954 & 1.41722 & 4.4 & 4.7 & 4.7 & 5.2 \\
\hline 89 & 23.13 & 87.43 & 23.58 & 87.46 & 5.2 & 50.9605 & 1.93649 & 4.6 & 5.2 & 5.2 & 5.7 \\
\hline 90 & 23.66 & 87.00 & 23.78 & 87.36 & 4.3 & 41.8027 & 1.58850 & 4.4 & 4.3 & 4.3 & 4.8 \\
\hline 91 & 22.14 & 87.73 & 22.68 & 87.91 & 4.5 & 63.9155 & 2.42878 & 4.8 & 4.5 & 4.5 & 5.0 \\
\hline 92 & 22.68 & 87.73 & 24.04 & 87.90 & 6.3 & 152.286 & 5.78688 & 5.4 & 6.3 & 6.3 & 6.8 \\
\hline 93 & 21.67 & 87.58 & 21.81 & 87.79 & 5.5 & 28.5474 & 1.08480 & 4.1 & 5.5 & 5.5 & 6.0 \\
\hline 94 & 20.80 & 86.90 & 21.00 & 86.99 & 4.5 & 24.1523 & 0.91778 & 4.0 & 4.5 & 4.5 & 5.0 \\
\hline 95 & 23.08 & 86.28 & 23.51 & 86.53 & 5.3 & 55.3257 & 2.10237 & 4.7 & 5.3 & 5.3 & 5.8 \\
\hline 96 & 22.94 & 85.76 & 23.11 & 86.98 & 5.4 & 135.949 & 5.16606 & 5.3 & 5.4 & 5.4 & 5.9 \\
\hline 97 & 24.00 & 90.70 & 24.95 & 91.90 & 7.5 & 170.098 & 6.46374 & 5.5 & 7.5 & 7.6 & 8.0 \\
\hline 98 & 24.08 & 90.24 & 24.91 & 90.84 & 6.5 & 113.146 & 4.29957 & 5.2 & 6.5 & 6.5 & 7.0 \\
\hline 99 & 25.15 & 89.96 & 25.29 & 92.91 & 7.5 & 328.214 & 12.4721 & 6.0 & 7.5 & 7.6 & 8.0 \\
\hline 100 & 25.19 & 90.78 & 26.04 & 90.80 & 8.4 & 93.6961 & 3.56045 & 5.1 & 8.5 & 9.3 & 9.3 \\
\hline 101 & 25.77 & 92.16 & 26.78 & 92.94 & 5.5 & 141.856 & 5.39054 & 5.4 & 5.5 & 5.5 & 6.0 \\
\hline 102 & 26.32 & 90.97 & 26.53 & 91.84 & 6.5 & 99.2327 & 3.77084 & 5.1 & 6.5 & 6.5 & 7.0 \\
\hline
\end{tabular}


Table 5. (Continued.)

\begin{tabular}{|c|c|c|c|c|c|c|c|c|c|c|c|}
\hline \multirow[b]{3}{*}{ Sl. no. } & & & & & \multirow{3}{*}{$\begin{array}{c}\mathrm{M}_{\mathrm{W}} \\
\text { observed } \\
\text { in the } \\
\text { fault }\end{array}$} & \multicolumn{3}{|c|}{ Method-A } & \multirow{3}{*}{$\begin{array}{c}\text { Method-B } \\
\mathrm{M}_{\max }, \text { by } \\
\text { incremental } \\
\text { value } \\
\text { (Gupta 2002) }\end{array}$} & \multirow{3}{*}{$\begin{array}{c}\text { Method-C } \\
\text { (Kijko } \\
\text { and Sellevol } \\
\text { 1989) }\end{array}$} & \multirow{3}{*}{$\begin{array}{l}\mathrm{M}_{\max } \\
\text { considered } \\
\text { for the } \\
\text { present } \\
\text { study }\end{array}$} \\
\hline & \multicolumn{4}{|c|}{ Fault coordinates } & & $\begin{array}{l}\text { Length } \\
\text { of fault } \\
\text { (TFL) }\end{array}$ & $\begin{array}{c}\text { SRL } \\
3.8 \% \text { of } \\
\text { TFL }\end{array}$ & & & & \\
\hline & Lat. & Long. & Lat. & Long. & & $(\mathrm{km})$ & $(\mathrm{km})$ & $\mathrm{M}_{\max }$ & & & \\
\hline 103 & 25.00 & 89.80 & 26.22 & 89.98 & 7.5 & 136.397 & 5.18309 & 5.3 & 7.5 & 7.6 & 8.0 \\
\hline 104 & 25.43 & 85.28 & 26.47 & 86.47 & 8.4 & 174.733 & 6.63986 & 5.5 & 8.5 & 9.3 & 9.3 \\
\hline 105 & 26.02 & 88.81 & 27.33 & 89.47 & 6.5 & 163.317 & 6.20606 & 5.5 & 6.5 & 6.5 & 7.0 \\
\hline 106 & 25.66 & 90.93 & 26.46 & 91.99 & 8.4 & 147.271 & 5.59632 & 5.4 & 8.5 & 9.3 & 9.3 \\
\hline 107 & 26.77 & 86.07 & 27.64 & 90.37 & 8.5 & 487.216 & 18.5142 & 6.3 & 8.5 & 7.8 & 9.0 \\
\hline 108 & 26.78 & 90.38 & 27.89 & 94.00 & 6.5 & 420.546 & 15.9807 & 6.2 & 6.5 & 6.5 & 7.0 \\
\hline 109 & 26.73 & 84.99 & 28.54 & 86.99 & 6.5 & 299.881 & 11.3955 & 5.9 & 6.5 & 6.5 & 7.0 \\
\hline 110 & 27.30 & 87.02 & 28.71 & 88.15 & 5.5 & 200.837 & 7.63181 & 5.6 & 5.5 & 5.5 & 6.0 \\
\hline 111 & 28.13 & 87.15 & 28.99 & 88.42 & 5.5 & 170.941 & 6.49577 & 5.5 & 5.5 & 5.5 & 6.0 \\
\hline 112 & 26.10 & 93.84 & 27.48 & 96.00 & 5.5 & 284.630 & 10.8159 & 5.9 & 5.5 & 5.5 & 6.0 \\
\hline 113 & 25.15 & 92.94 & 25.99 & 94.13 & 6.5 & 160.783 & 6.10976 & 5.5 & 6.5 & 6.5 & 7.0 \\
\hline 114 & 28.07 & 94.00 & 29.06 & 96.00 & 6.5 & 246.605 & 9.371 & 5.8 & 6.5 & 6.5 & 7.0 \\
\hline
\end{tabular}

Method-C: Method to estimate $\mathrm{M}_{\max }$ proposed by Kijko and Sellevol (1989) is applicable only when the ' $b$ ' value of seismicity parameter of the region is known. The method has been established using the doubly truncated $\mathrm{G}-\mathrm{R}$ relation as given below.

$M_{\max }=M_{\max }^{\mathrm{obs}}+\frac{E_{1}\left(n_{2}\right)-E_{1}\left(n_{1}\right)}{\beta \exp \left(-n_{2}\right)}+M_{\min } \exp (-n)$

where $M_{\max }$ is the upper bound maximum magnitude, $M_{\max }^{\mathrm{obs}}$ is the observed maximum magnitude in each fault, and $n$ is the total number of earthquakes of magnitude $\left(\mathrm{M}_{\mathrm{w}}>4\right)$. The $M_{\text {min }}$ denotes the minimum magnitude. In the present study, $M_{\text {min }}$ is taken as 4 , because below this magnitude, there is a less interest in engineering design.

However,

$$
\begin{aligned}
& n_{1}=\frac{n}{\left\{1-\exp \left[-\beta\left(m_{\max }-m_{\min }\right)\right]\right\}}, \\
& n_{2}=n_{1}\left\{\exp \left[-\beta\left(m_{\max }-m_{\min }\right)\right]\right\},
\end{aligned}
$$

and $E_{1}\left(n_{i}\right)$ expresses the exponential integration function that could be evaluated as:

$$
E_{1}(n)=\frac{n^{2}+a_{1} n+a_{2}}{n\left(n^{2}+b_{1} n+b_{2}\right)} \exp (-n),
$$

where $a_{1}, a_{2}, b_{1}, b_{2}$ are the constant coefficients (Abramowitz and Stegun 1970). The above method proposed by Kijko and Sellevol (1989) has been used by various researchers worldwide, including India, for seismic hazard studies. We have characterized the study area (northeast India) into six major seismic source zones and estimated seismicity parameters for each zone separately by considering the seismic events that occurred within the respective zones. These six ' $b$ ' value parameters were used for estimation of $M_{\max }$ using the above equation for each fault that lay within the respective zone. The maximum magnitude estimated for each fault obtained from the above methods is presented in table 5 .

\subsection{Seismic hazard assessment methodologies}

For calculating the seismic hazard values using both the DSHA and PSHA methodologies, the entire study area was divided into a grid size of $0.05^{\circ} \times 0.05^{\circ}$ and the hazard values at the center of each grid cell were calculated by considering all the identified seismic sources within a radius of $500 \mathrm{~km}$. Hazard analysis is based on linear sources as identified in figure 3. This grid size has been chosen to obtain a finer resolution of the hazard values in the study area with greater details for further study. In contrast, the purposes of calculating the hazards in each grid point are mainly because of the following reasons:

To assess the hazard, the entire study area was divided into a number of grid cells and the center of each grid cell is considered as a hazard point or location from all four sides of the grid. Now, considering every individual point as a site/location in space, the shortest distance is calculated for each source and finally, maximum hazard predicted value is selected from all the sources calculated for the study area of the particular location. However, applying interpolation technique, the delineation is done for the entire study area. The advantage of using this gridding technique is to have a simple linear mathematical relation to find out the required 
unknowns between the two known points in the space/plane.

Further, for seismic hazard assessment techniques, the deterministic methodology considers only the worst scenario (the largest magnitude) and the shortest distance from source to site; it provides a high value of hazard in terms of PGA, which normally does not occur in the life span of the common structures. However, the reason for using of MCE ensures that the effects from all other magnitudes are normally taken care of and that will automatically withstand all other magnitudes smaller than MCE. The California Geological Survey, developed a PGA map using this method for designing various projects (Greensfelder 1974). After the 1995 Kobe earthquake in Japan, a DSHA map of Japan was also published (Nishioka and Mualchin 1997). For hazard analysis, DSHA is known to have one of the simplest methods for seismic hazard evaluation (Maulchin 2005).

The occurrence of an earthquake within a seismic source is assumed to follow a Poisson distribution. In PSHA, the probability of ground motion parameter, $Z$, at a given site will exceed a specified level, $z$, during a specified time, $T$ is represented by the expression:

$$
P(Z>z)=1-e^{-\nu(z) T} \leq \nu(z) T
$$

where $\nu(z)$ is the mean annual rate of exceedance of ground motion parameter, $Z$, with respect to $z$. The function $\nu(z)$ incorporates the uncertainty in time, size, and location of future earthquakes and uncertainty in the ground motion they produce at the site. It is given by:

$$
\begin{aligned}
\nu(z) & =\sum_{n=1}^{N} N_{n}\left(m_{0}\right) \int_{m=m_{0}}^{m_{\max }} f_{n}(m) \\
& \times\left[\int_{r=0}^{\infty} f_{n}(r \mid m) P(Z>z \mid m, r) d r\right] d m
\end{aligned}
$$

where $N_{n}\left(m_{0}\right)$ is the frequency of earthquakes on a seismic source $n$, having a magnitude equal to or greater than a minimum magnitude $m_{0}$ (in this study it is taken as 4.0$) ; f_{n}(m)$ is the probability density function for a minimum magnitude of $m_{0}$ and a maximum magnitude of $m_{\max } ; f_{n}(r \mid m)$ is the conditional probability density function (probability of occurrence of an earthquake of magnitude $m$ at a distance $r$ from the site for a seismic source $n) ; P(Z>z \mid m, r)$ is the probability at which the ground motion parameter $Z$ exceeds a predefined value of $z$, when an earthquake of magnitude $m$ occurring at a distance of $r$ from the site. The integral in equation (6) can be replaced by summation and the density functions $f_{n}(m)$ and $f_{n}(r \mid m)$ can be replaced by discrete mass functions. The resulting expression for $\nu(z)$ is given by:

$$
\begin{aligned}
\nu(z) & \sum_{n=1}^{N} \sum_{m_{i}=m_{0}}^{m_{\max }} \lambda_{n}\left(m_{i}\right) \\
& \times\left[\sum_{r_{j}=r_{\min }}^{r_{\max }} P_{n}\left(R=r_{j} \mid m_{i}\right) P\left(Z>z \mid m_{i}, r_{j}\right)\right]
\end{aligned}
$$

where $\lambda_{n}\left(m_{i}\right)$ is the frequency of occurrence of magnitude $m_{i}$ at the source $n$ obtained by discretizing the earthquake recurrence relationship for the source $n$. Many uncertainties are associated with these models and hence, the logic tree approach was adopted after assessing the hazard using both the equations (Atkinson and Boore 2003; Gupta 2010) with 60\% (Gupta 2010 inslab, as a region specific GMPE) and 40\% (Atkinson and Boore 2003 inslab) weighting factors in order to get a rational value of hazard from these different uncertainties. In other words, higher weightage is given to Gupta (2010), because, it is a region specific GMPE developed in northeast India and this equation can predict reasonable hazard values at large distances, but the Atkinson and Boore (2003), predicts well at short distances whereas, it underestimates hazard at large distances (figure 7). However, considering that the study area like Tripura is located at a moderate distance from IBR and EH zones, Gupta (2010) has given higher weightage to have a better assessment of the hazard.

\section{Results and discussion}

In this paper, the results are presented using both the DSHA and PSHA methodologies for Tripura and Mizoram states at bedrock level condition. The declustering of events, homogenization, and data completeness analysis have been carried out before hazard evaluation and seismicity parameters were estimated using $\mathrm{G}-\mathrm{R}$ relationship (table 4 ). In seismic hazard assessment, DSHA provides comparatively higher values than PSHA and this issue has often been raised by several researchers. Finally, it has been proposed that DSHA to be used for evaluating hazard in critical infrastructural projects (Reiter 1990; Kramer 1996, Committee on seismic risk 1984, EERI). However, the variation may be because of different assumptions in methodologies adopted in both the approaches (DSHA and PSHA), whereas inputs are almost same in both the cases. The main features about the method 


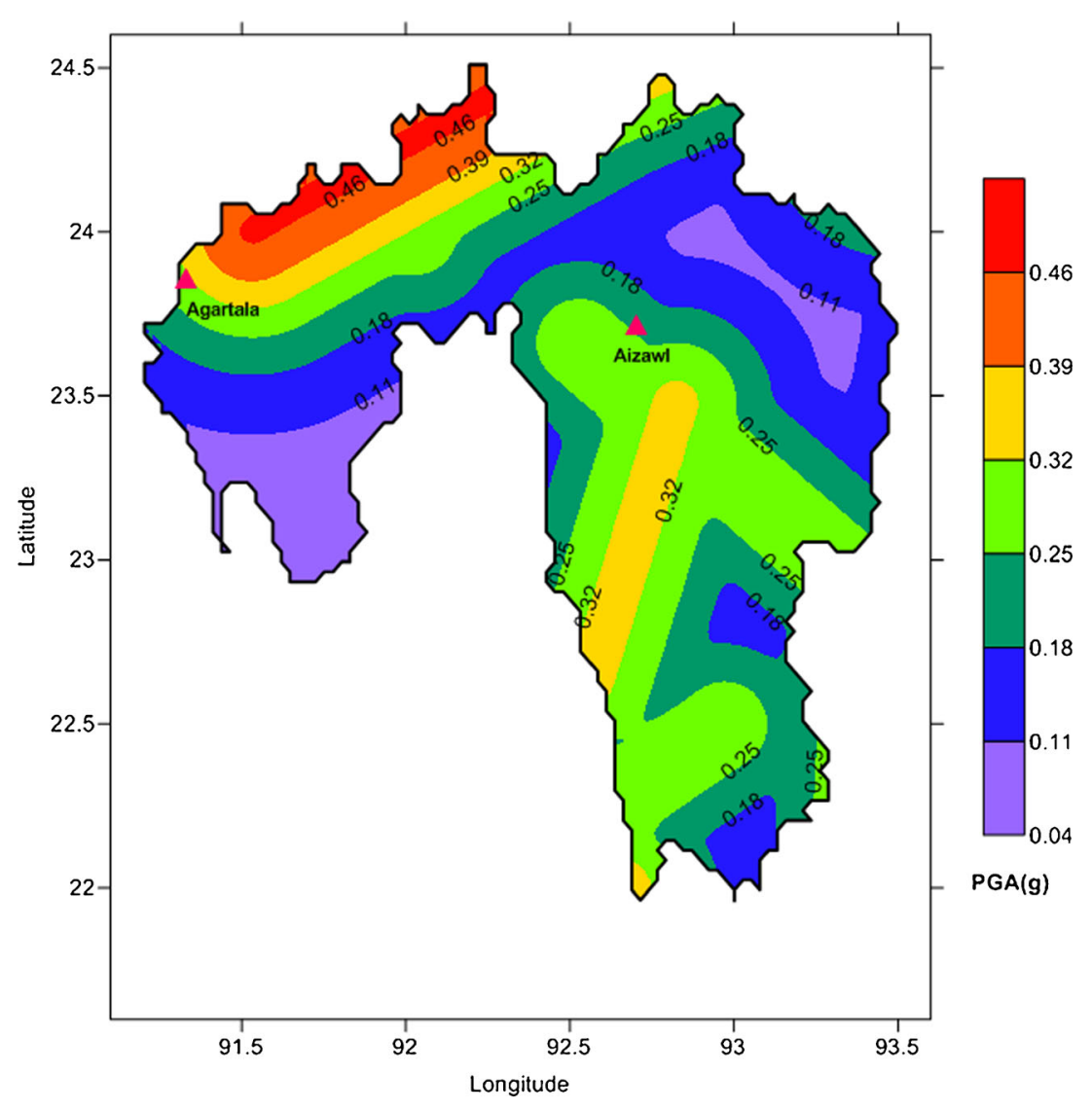

Figure 8. PGA map of Tripura and Mizoram states based on DSHA.

Table 6. Comparison of PGA value with the present study and other reported results.

\begin{tabular}{lcccccc}
\hline \multirow{2}{*}{ Location } & \multicolumn{2}{c}{ Present study } & $\begin{array}{c}\text { Das et al. } \\
(2006)\end{array}$ & $\begin{array}{c}\text { Iyengar } \\
(2010)\end{array}$ & $\begin{array}{c}\text { Parvez } \text { et al. } \\
(2003)\end{array}$ & $\begin{array}{c}\text { BIS-1893 (2002) } \\
\text { India }\end{array}$ \\
\cline { 2 - 6 } Agartala (Capital of Tripura) & $0.11-0.22 \mathrm{~g}$ & $0.29 \mathrm{~g}$ & $0.18-0.22 \mathrm{~g}$ & $0.12-0.18 \mathrm{~g}$ & $0.15-0.3 \mathrm{~g}$ & $\mathrm{ZPA}=0.18 \mathrm{~g}$ \\
Aizwal (Capital of Mizoram) & $0.11-0.17 \mathrm{~g}$ & $0.24 \mathrm{~g}$ & $0.22-0.28 \mathrm{~g}$ & $0.22-0.35 \mathrm{~g}$ & $0.15-0.3 \mathrm{~g}$ & $\mathrm{ZPA}=0.18 \mathrm{~g}$ \\
\hline
\end{tabular}

ZPA - Zero period acceleration.

of analyses between the DSHA and PSHA can be listed below:

\subsection{DSHA}

A basic DSHA is a simple process that is useful especially where tectonic features are reasonably active and well defined. The focus is generally in determining the maximum credible earthquake (MCE) motion at the site. DSHA is frequently used in California and Japan due to the knowledge of faults and the region's high seismicity. The main features in the process are as follows (Kramer 1996):

- DSHA provides maximum PGA

- Identifies major vulnerable sources
- Identifies MCE

- Uncertainties are not accounted

- Considers worst scenario $\left(\mathrm{R}_{\min }, \mathrm{M}_{\mathrm{w}} \max \right)$

\subsection{PSHA}

- Uncertainties considered in PSHA by a probability distribution at each step.

- When will an earthquake occur?

. How big will it be?

- Where will it occur?

- What will be the strength of the seismic waves when it reaches the site?

- Provides user choice.

However, PSHA for Tripura and Mizoram states has been carried out after estimating the seismicity 


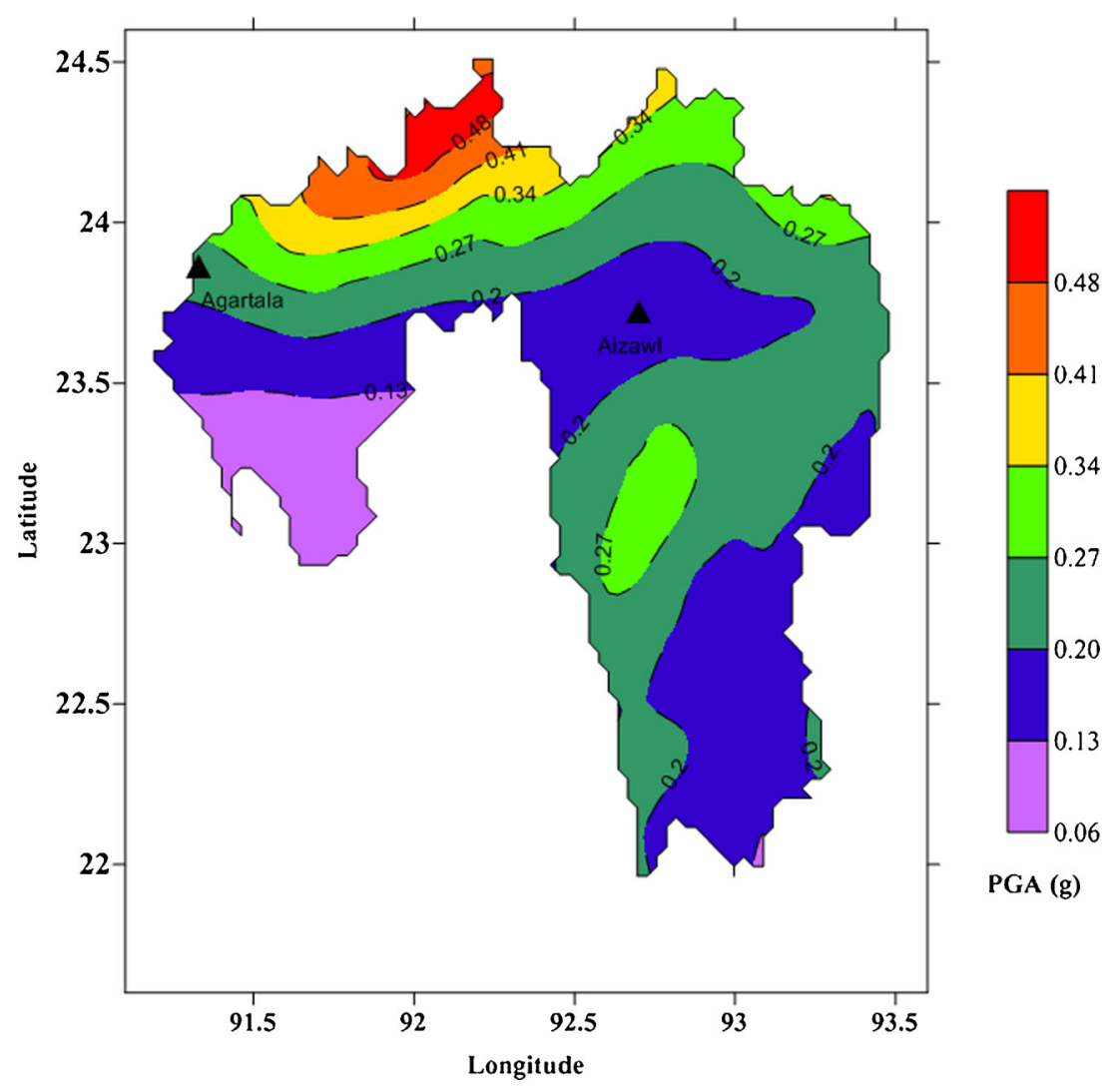

Figure 9. Spatial variation of PGA at rock level for $2 \%$ probability of exceedance in 50 years.

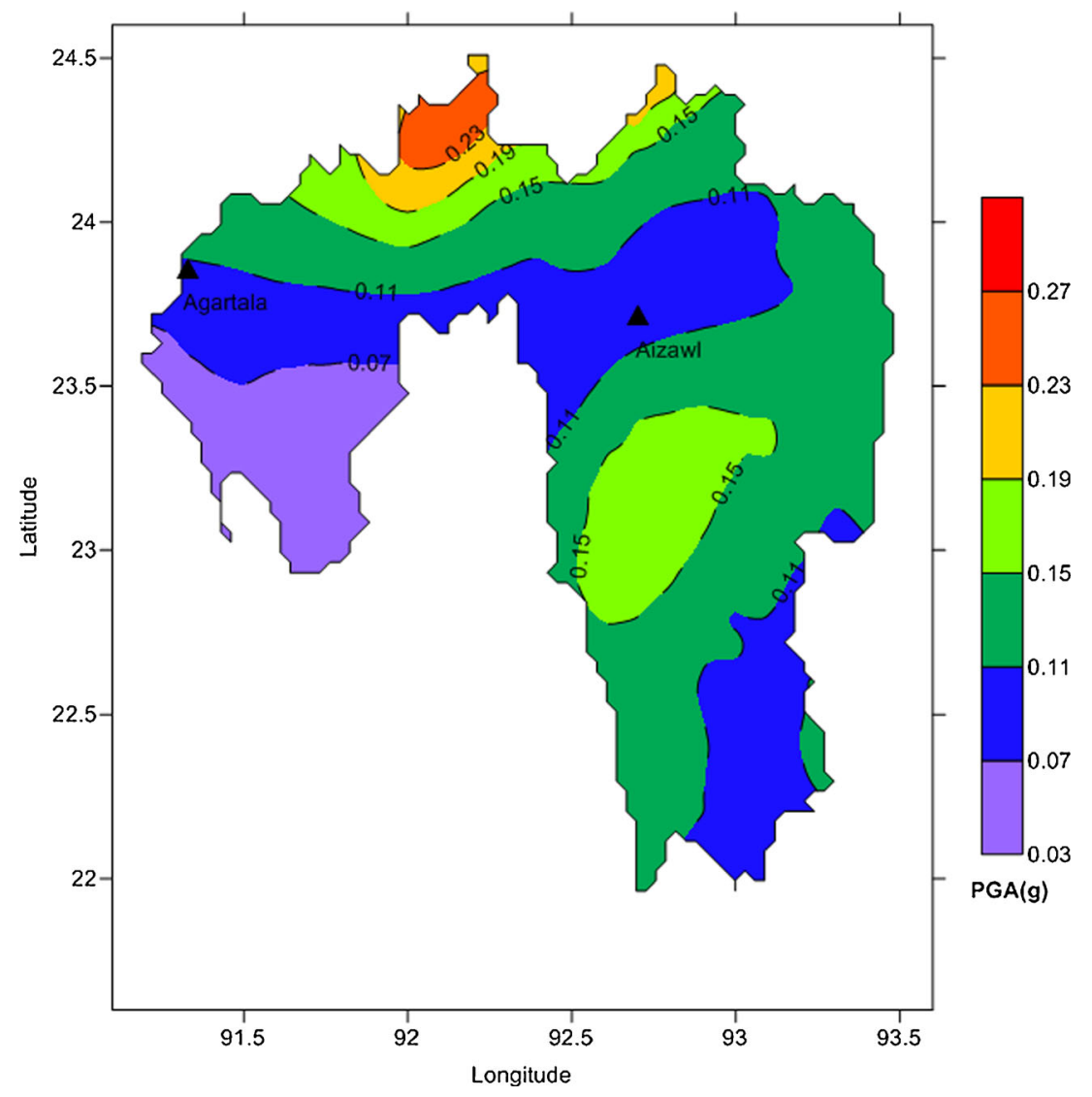

Figure 10. Spatial variation of PGA at rock level for $10 \%$ probability of exceedance in 50 years. 


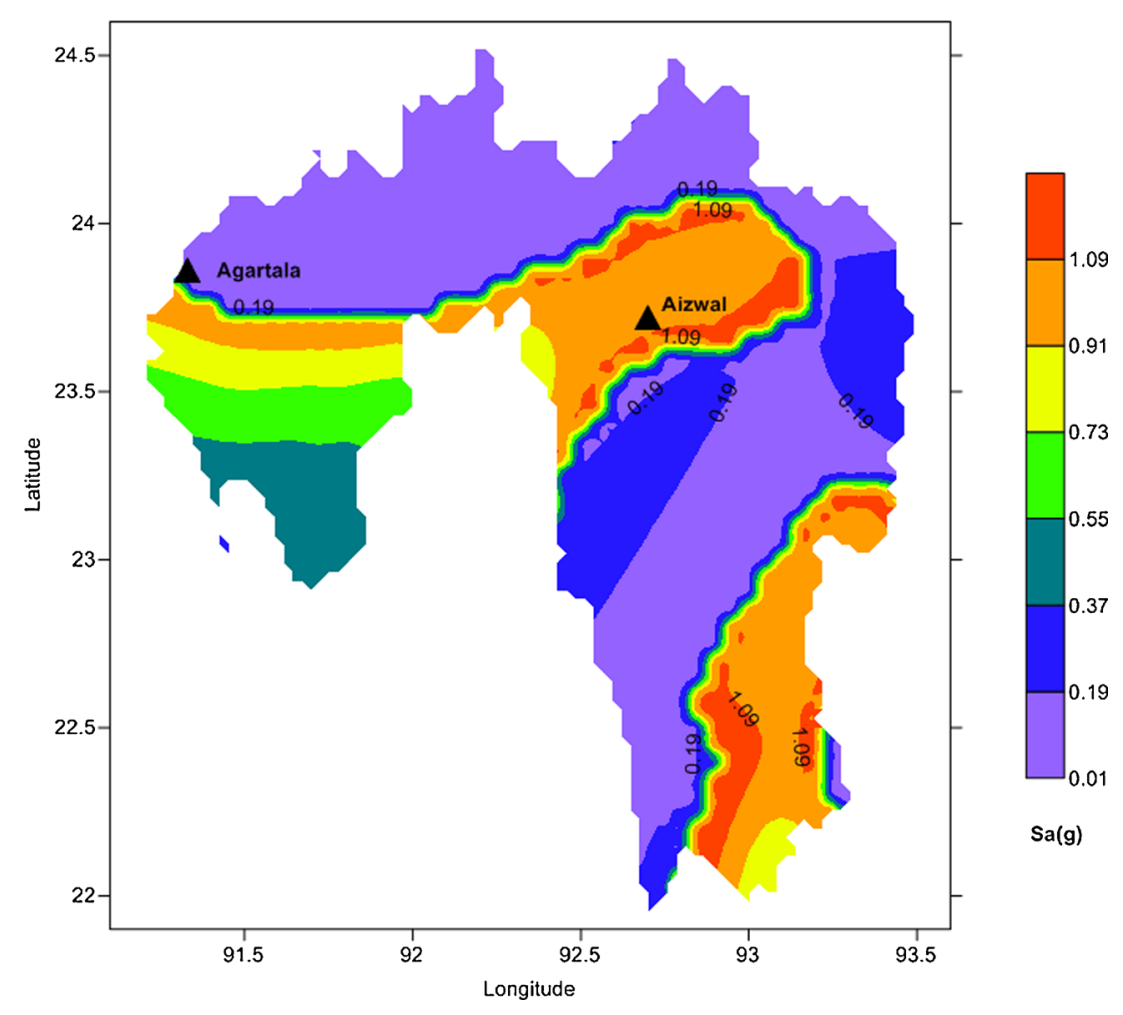

Figure 11. Rock level spectral acceleration $(\mathrm{T}=0.2 \mathrm{~s}) 5 \%$ damping with $2 \%$ probability of exceedence in 50 years.

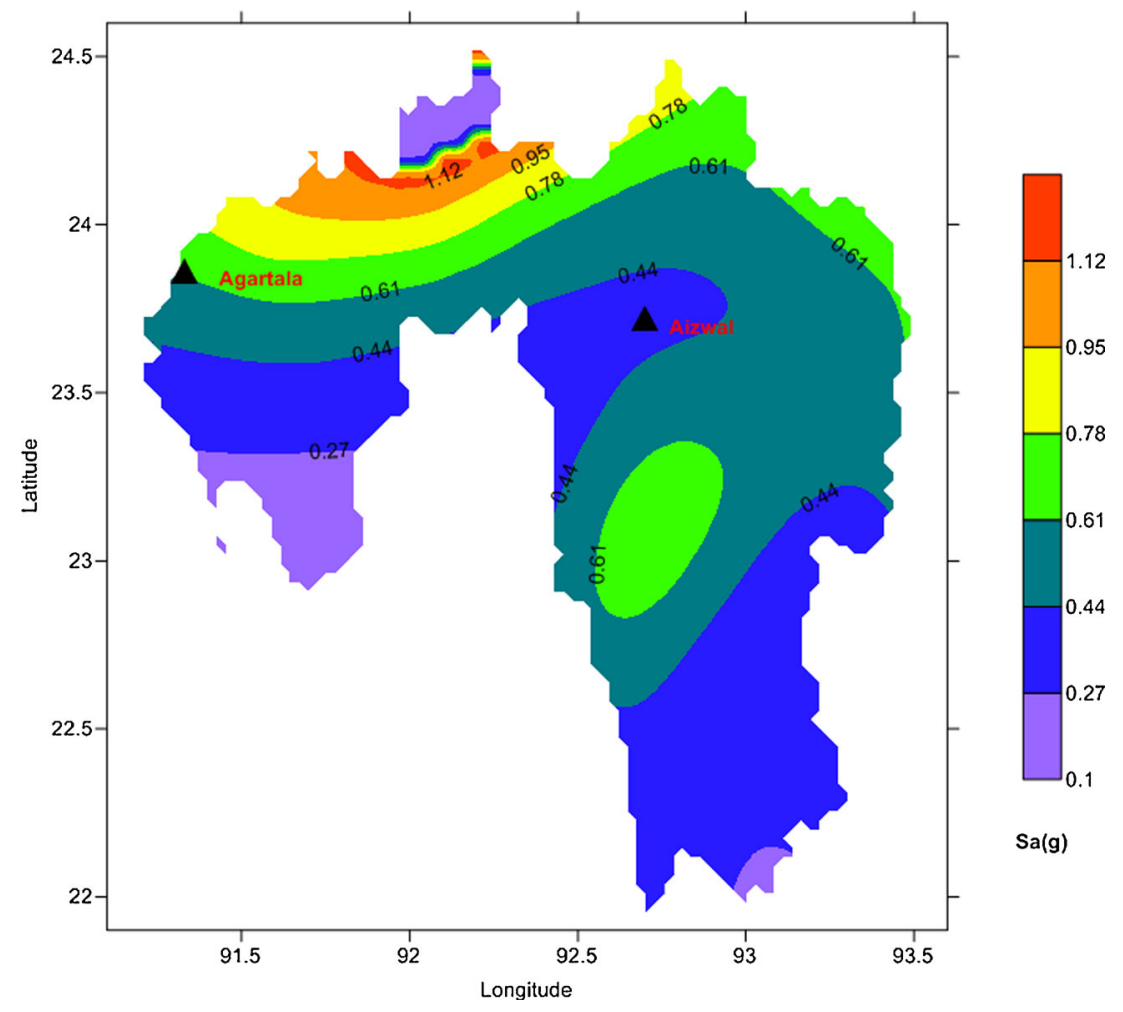

Figure 12. Rock level spectral acceleration ( $\mathrm{T}=1.0 \mathrm{~s}$ ) $5 \%$ damping with $2 \%$ probability of exceedence in 50 years.

parameters for each seismogenic source. Attenuation relations were validated with the recorded PGA values before they were used in the hazard analysis. The Gupta (2010) inslab and Atkinson and Boore (2003) inslab equations were used for present hazard assessment. The PGA at the rock 
level was estimated at the center of each grid cell considering the grid size $0.05^{\circ} \times 0.05^{\circ}$ through DSHA and PSHA methodologies for the entire study area. The DSHA results showing the spatial variations of PGA were presented in figure 8 . The PSHA contour maps showing the spatial variation of PGA ( $2 \%$ and $10 \%$ probabilities) values and spectral accelerations $(0.2 \mathrm{~s}, 1.0 \mathrm{~s})$ were also evaluated.

In DSHA, the higher PGA values were observed in the north part of Tripura having PGA 0.39-0.53 $\mathrm{g}$ in $\mathrm{N}-\mathrm{W}$ direction; whereas lowest hazard ranges were found in the south part of Tripura having PGA 0.04-0.11 g. In Mizoram state, the comparatively high hazard level is observed in mid-central part of the state having PGA value ranging from 0.32-0.39 g (figure 8). However, the PGA (based on DSHA) for Agartala and Aizwal cities were found to be 0.29 and $0.24 \mathrm{~g}$, respectively (table 6 ). The PGA distribution maps (based on PSHA) for $2 \%$ and $10 \%$ probability of exceedance in 50 years are shown in figures 9 and 10 . The PGA values for Tripura vary from $0.06-0.54 \mathrm{~g}$ ( $2 \%$ probability of exceedance) and $0.03-0.31 \mathrm{~g}$ ( $10 \%$ probability of exceedance). Similarly, the PGA values for Mizoram vary from $0.13-0.41 \mathrm{~g}$ ( $2 \%$ probability of exceedance) and $0.08-0.23 \mathrm{~g}$ ( $10 \%$ probability of exceedance).

Further, spatial variation of rock level spectral acceleration ( $\mathrm{T}=0.2 \mathrm{~s}$ and $1.0 \mathrm{~s}$ ) of $5 \%$ damping with $2 \%$ probability of exceedance in 50 years were evaluated for both the states which are shown in figures 11 and 12. The higher spectral acceleration (Sa) was found near Aizawl city and its surrounding having the values $(\mathrm{Sa}>0.91 \mathrm{~g})$ at short period $(0.2 \mathrm{~s})$ for a $2 \%$ probability of exceedance; implying that the short period structures will be severely affected by high hazard $(>1.0 \mathrm{~g})$, which is a velocity sensitive area. In figure 11 , high severity is observed in places, which are in moderate distance from the controlling sources. Therefore, infrastructure should be designed accordingly after considering this parameter (velocity) as a high priority while designing. The spectral acceleration $(0.2 \mathrm{~s})$ found in Agartala city having $0.19-0.36 \mathrm{~g}$ ( $2 \%$ probability of exceedance), which implies comparatively low hazard for short periods. However, the higher spectral acceleration was found in the north part of the Tripura state $(\mathrm{Sa}>1.0 \mathrm{~g}$ ) for longer periods $(1.0 \mathrm{~s})$; indicating that the structures (longer period) will be affected much (bridges, overhead tanks (OHT), and multistoried building). The low hazard $(0.1-0.27 \mathrm{~g})$ is also found in a small portion of north and south parts of the state. The spectral acceleration across the Mizoram state ranges between 0.1 and $0.95 \mathrm{~g}$ ( $2 \%$ probability of exceedance) for longer periods. In both DSHA and PSHA results, northern part of Tripura has been found to have high hazard compared to other parts. This part is very close to Sylhet (Bangladesh) fault which had two major earthquakes $\mathrm{M}_{\mathrm{w}}>7$ in the past. The PGA values obtained using both the methods have a close agreement with other reported results which are shown in table 6 .

\section{Conclusions}

In this study, an attempt has been made to develop updated seismic hazard maps for Tripura and Mizoram states using DSHA and PSHA methodologies. All the hazard maps were generated considering updating earthquake catalogue collected since 1731-2011 and using recently characterized six potential proposed seismic source zones by the authors. We have homogenized all the collected events based on region-specific correlations developed. The new hazard maps show expected seismic hazard values and provide a basis for the planning of long-term preparedness for earthquake hazards and mitigation. These maps can be used as a direct input in site response study to know the surface level hazard. These maps also provide useful information for other purposes, such as estimation of earthquake insurance premium, identifying most vulnerable locations and selection of an appropriate location for important infrastructure and the most possible severe locations for detailed sitespecific evaluation of seismic hazards. The hazard map developed using both the methods (DSHA and PSHA) provides a clear idea about the measure of variability or degree of uncertainty/errors involved in the estimated hazard values for a location in a quantitative manner/form. The DSHA predicts on the higher side when compared to PSHA (table 6). The PSHA for Tripura and Mizoram evaluated at a micro level compared reasonably well with other researchers for northeast India (which were done reasonably on a macro scale). We used region-specific GMPE for hazard evaluation developed by Gupta (2010) for northeast India for subduction zone and Atkinson and Boore (2003) model using the global database after validation. We hope that the seismic hazard analysis presented here is an important step towards an accurate evaluation of seismic hazard potential in the study area.

\section{References}

Abramowitz M and Stegun I A 1970 Handbook of mathematical functions, 9th edn, Dover Publication, New York.

Atkinson G M and Boore D M 2003 Empirical ground motion relations for subduction zone earthquakes and their application to Cascadia and other regions; Bull. Seismol. Soc. Am. 93 1703-1729. 
BIS-1893-2002 Indian Standard Criteria for Earthquake Resistant Design of Structures, Part 1 - General Provisions and Buildings, Bureau of Indian Standards, New Delhi.

Basu K L 1964 A note on the Coimbatore earthquake of 8th February 1900; Indian J. Meteorol. Geophys. 15(2) 281-286.

Bilham R 2004 Earthquakes in India and the Himalaya: Tectonics, geodesy and history; Ann. Geophys. 47839 858.

Boominathan A 2011 Seismic hazard assessment for the proposed $2 \times 500 \mathrm{Mw}$ Fast Breeder Reactor $-1 \times 2$, Kalpakkam Draft Report, A, IIT Madras, June 2011.

Chandra U 1977 Earthquakes of peninsular India - a seismotectonic study; Bull. Seismol. Soc. Am. 67 13871413.

Cornell C A 1968 Engineering seismic risk analysis; Bull. Seismol. Soc. Am. 58 1583-1606.

Das S, Gupta I D and Gupta V K 2006 A probabilistic seismic hazard analysis of northeast India; Earthquake Spectra 22(1) 1-27.

Dunbar P K, Lockridge P A and Whiteside L S 1992 Catalogue of significant earthquakes, 2150 B.C.-1991 A.D.; NOAA/NGDC Report SE-49. Boulder, Colorado, 320p.

Gardner J K and Knopoff L 1974 Is the sequence of earthquakes in southern California with aftershocks removed, Poissonian?; Bull. Seismol. Soc. Am. 64(5) 1363-1367.

Greensfelder R W 1974 Maximum credible rock acceleration from earthquakes in California; California Department of Conservation, Division of Mines and Geology Map Sheet $23,12 \mathrm{p}$.

Gupta I D 2002 The state-of-the-art in seismic hazard analysis; ISET J. Earthquake Technol. 39(4) 311-346.

Gupta I D 2006 Delineation of probable seismic sources in India and neighbourhood by a comprehensive analysis of seismotectonic characteristics of the region; Soil Dyn. Earthq. Eng. 26 766-790.

Gupta I D 2010 Response spectral attenuation relations for inslab earthquakes in Indo-Burmese subduction zone; Soil Dyn. Earthq. Eng. 30 368-377.

Gutenberg B and Richter C F 1944 Frequency of earthquakes in California; Bull. Seismol. Soc. Am. 34 185-188.

Iyengar R N 2010 Development of probabilistic seismic hazard map of India; A technical report of the working committee of experts (WCE) constituted by the National Disaster Management Authority, Govt. of India, New Delhi.

Iyengar R N and Ghosh S 2004 Microzonation of earthquake hazard in Greater Delhi area; Curr. Sci. 87 1193-1202.

Jaiswal K and Sinha R 2007a Probabilistic seismic hazard estimation for peninsular India; Bull. Seismol. Soc. Am. 97(1) 318-330.

Jaiswal K and Sinha R 2007b Spatial variation of maximum considered and design basis earthquakes in peninsular India; Curr. Sci. 92(5) 639-645.

Jaiswal K and Sinha R 2008 Spatial-temporal variability of seismic hazard in peninsular India; J. Earth Syst. Sci. 117(S2) 707-718.

Kayal J R 1987 Microseismicity and source mechanism study: Shillong Plateau, northeast India; Bull. Seismol. Soc. Am. 77 184-194.

Kayal J R 1998 Seismicity of northeast India and surroundings - development over the past 100 years; J. Geophys. 19(1) 9-34.

Khattri K N and Weiss M 1978 Precursory variation of seismic rate in Assam area, India; Geology 6 685-688.

Khattri K N and Tyagi A K 1993 Seismicity patterns in the Himalayan plate boundary and identification of the areas of high seismic potential; Tectonophys. 96 281-297.
Kijko A and Sellevol M A 1989 Estimation of earthquake hazard parameters from incomplete data files, Part I: Utilization of extreme and complete catalogues with different threshold magnitudes; Bull. Seismol. Soc. Am. 40 1-7.

Kolathayar S and Sitharam T G 2012 Characterization of seismic sources in and around India; Seismol. Res. Lett. 83(1) $77-85$.

Kolathayar S, Sitharam T G and Vipin K S 2012 Deterministic seismic hazard macrozonation of India; J. Earth Syst. Sci. 121(5) 1351-1364.

Kramer S L 1996 Geotechnical earthquake engineering; International Series in Civil Engineering and Engineering Mechanics, Prentice-Hall, New Jersey.

Kumar N, Parvez I A and Virk H S 2005 Estimation of coda waves attenuation for NW Himalayan region using local earthquakes; Phys. Earth Planet. Interiors 3 243-258.

Kumar P, Yuan X, Ravi Kumar M, Kind R, Li X and Chadha R K 2007 The rapid drift of Indian tectonic plate; Nature 449 894-897.

Maulchin L 2005 Seismic hazard analysis for critical infrastructures in California; J. Eng. Geol. 79 177-184.

Menon A, Ornthammarath T, Corigliano M and Lai C G 2010 Probabilistic seismic hazard macrozonation of Tamil Nadu in southern India; Bull. Seismol. Soc. Am. 100(3) 1320-1341.

Mitra S, Priestley K, Bhattacharyya A K and Gaur V K 2005 Crustal structure and earthquake focal depths beneath north eastern India and south Tibet; Geophys. J. Int. 160 227-248.

Mueller C S 2010 The influence of maximum magnitude on seismic hazard estimates in the central and eastern United States; Bull. Seismol. Soc. Am. 100(2) 699-711.

Mukhopadhyay M 1992 On earthquake focal mechanism studies for the Burmese arc; Curr. Sci. 1 72-88.

Mukhopadhyay M and Dasgupta S 1988 Deep structure and tectonics of the Burmese arc: Constraints from earthquake and gravity data; Tectonophys. 149 299-322.

Nandy D R 2001 Geodynamics of north-eastern India and the adjoining region; ABC Publications, Calcutta, 209p.

Nath S K 2006 Seismic hazard and microzonation atlas of the Sikkim Himalaya; Department of Science and Technology, Government of India, New Delhi, India.

Nath S K 2007 Seismic microzonation atlas of Guwahati region; Department of Science \& Technology, Government of India, New Delhi.

Nath S K and Thingbaijam K K S 2011 Peak ground motion predictions in India: An appraisal for rock sites; J. Seismol. 15 295-315.

Nath S K, Raj A, Thingbaijam K K S and Kumar A 2009 Ground motion synthesis and seismic scenario in Guwahati city - a stochastic approach; Seismol. Res. Lett. 80 233-242.

Nath S K, Thingbaijam K K S and Raj A 2011 Earthquake hazard in the northeast India. A seismic microzonation approach with typical case studies from Sikkim, Himalaya and Guwahati city; National Workshop on Earthquake Risk Mitigation Strategy in North-East, Guwahati, Assam, India.

Nishioka T and Mualchin L 1997 Deterministic seismic hazard map of Japan from inland maximum crediable earthquakes for engineering; J. Struct. Eng./Earthquake Eng. Japan Soc. Civil Eng. 14.

NDMA 2010 Development of probabilistic seismic hazard map of India; Technical report by National Disaster Management Authority, Govt. of India.

Oldham R D 1883 A catalogue of Indian earthquakes from the earliest time to the end of A.D. 1869 (eds) Thomas Oldham and R D Oldham, Geol. Soc. India Memoir, pp. $163-215$. 
Oldham R D 1899 Report on the great earthquake of 12 June 1897; Geol. Soc. India Memoir, 379p.

Pallav K 2010 Seismic microzonation of Imphal City and probabilistic seismic hazard assessment of Manipur state; PhD Thesis, IIT Guwhati, Assam, India.

Parvez I A, Vaccari F and Panza G F 2003 A deterministic seismic hazard map of India and adjacent areas; Geophys. J. Int. 155 489-508.

PCRSMJUA 2005 Project completion report of seismic microzonation of Jabalpur Urban Area; vol. 2, Department of Science and Technology, Government of India, India.

Reiter L 1990 Earthquake hazard analysis: Issues and insights; Columbia University Press, New York, USA.

Raghu Kanth S T G and Dash S K 2010 Deterministic seismic scenarios for northeast India; J. Seismol. 14 143-167.

Raghu Kanth S T G and Iyengar R N 2006 Seismic hazard estimation for Mumbai city; Curr. Sci. 11 1486-1494.

Raghu Kanth S T G and Iyengar R N 2007 Estimation of seismic spectral acceleration in peninsular India; J. Earth Syst. Sci. 116(3) 199-214.

Raghu Kanth S T G, Sreelatha S and Dash Sujit Kumar 2008 Ground motion estimation at Guwahati city for an $\mathrm{M}_{\mathrm{w}} 8.1$ earthquake in the Shillong Plateau; Tectonophys. 448 98-114.

Rastogi B K 1974 Earthquake mechanisms and plate tectonics in the Himalayan region; Tectonophys. 21 47-56.

RMS 2011 Estimating insured losses from the 2011 Tohoku, Japan earthquake and tsunami; Risk Manag. Solut. (special report).

Rydelek P A and Sacks I S 1989 Testing the completeness of earthquake catalogues and the hypothesis of self-similarity; Nature 337 251-253.

Roshan A D and Basu P C 2010 Application of PSHA in low seismic region: A case study on NPP site in peninsular India; Nucl. Eng. Des. 240 3443-3454.
Steep J C 1972 Analysis of completeness of the earthquake sample in the Puget sound area and its effects on statistical estimates of earthquake hazard; Proc. Inter. Conf. Microzonation for Safer Construct. Res. Appl., Seattle, Washington 64(4) 1189-1207.

SEISAT 2000 Seismotectonic Atlas of India, Geological Survey of India, New Delhi.

Sitharam T G and Anbazhagan P 2009 Report on Seismic Microzonation of Bangalore Urban Centre; Seismology Division, Main Volume, Ministry of Earth Sciences, Government of India, Printed in Bangalore, India, 174p.

Sitharam T G and Vipin K S 2011 Evaluation of spatial variation of peak horizontal acceleration and spectral acceleration for south India: A probabilistic approach; Nat. Hazards 59 639-653.

Suganthi A and Boominathan A 2006 Seismic response study of Chennai city using geotechnical borelog data and GIS; In: Proceedings on the Indian Geotechnical Conference 2006, 14-16 December, Chennai, India, pp. 831-832.

Tandon A N and Srivastava H N 1975 Focal mechanism of some recent Himalayan earthquakes and regional plate tectonics; Bull. Seismol. Soc. Am., pp. 963-969.

Tiwari R P 2000 Earthquake hazards and mitigation in India with special reference to north-eastern India; ENVIS Bull. 8(2) $15-22$.

Uhrhammer R A 1986 Characteristic of northern and central California seismicity (abstract); Earthquake Notes $1,21$.

Wheeler R L 2009 Methods of $\mathrm{M}_{\max }$ estimation east of the Rocky Mountains; U.S. Geological Survey Open-File Report 2009-1018, 44p. (http://pubs.usgs.gov/of/2009/ 1018/pdf/OF09-1018.pdf).

Wells D L and Coppersmith K J 1994 New empirical relationships among magnitude, rupture length, rupture width, rupture area, and surface displacement; Bull. Seismol. Soc. Am. 84 974-1002. 